\title{
Stress concentration factor and fatigue analysis of a lateral nozzle with local wall thinning
}

\author{
Xiaohui Chen ${ }^{\mathrm{a}, \mathrm{b}^{*}}$, Shuang Fang ${ }^{\mathrm{a}}$, Haofeng Chen $^{\mathrm{c}}$

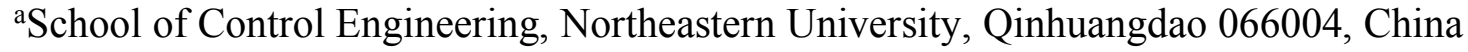 \\ ${ }^{\mathrm{b} S}$ School of Mechanical Engineering \& Automation, Yanshan University, Qinhuangdao, \\ 066004, China
}

'Department of Mechanical \& Aerospace Engineering, University of Strathclyde, G1 1XJ, UK

*Corresponding author: Xiaohui Chen

Email address: chenxh@neuq.edu.cn 


\begin{abstract}
After long-term service, metallic pipe components in nuclear power plant, chemical, petroleum industries will experience wear, leading to wall thinning. Severe thinning would affect the structural integrity, and thus a capability was required to assess the thinned components. The greatest weakening was normally near pressurized cylinder and nozzle intersection. In this study, the finite element method was used to determine the remaining structural capacity of lateral nozzles which had been subjected to local wall thinning. The study was divided into two main parts; a stress analysis at the lateral nozzles and piping having wall thinning, and a fatigue analysis of damaged intersections subject to cyclical loading. A finite element analysis (FEA) was carried out for the cylinder-nozzle intersections, to determine the stress concentration factor (SCF). 3D elements were used for the lateral nozzles. An evaluation was made of the effect on the SCF and fatigue damage coefficient of the growth of the thinning away from the intersection. Finally, a parametric study was conducted in which the SCF was computed for a number of intersections, initially considered undamaged, and then with wall thinning damage. Charts based on the results are provided for the convenience of engineers. A preliminary fatigue analysis was carried out to compare the performance under internal pressure of cylinder-nozzle intersections, without and with wall thinning damage. According to orthogonal design method, orthogonal table L9 $\left(3^{4}\right)$ was established in order to analyze the SCF and fatigue damage coefficient of lateral nozzle with local wall thinning. Dimensionless relation of SCF, fatigue damage coefficient and defect length, defect depth, defect width and the angle of the cylinder and nozzle was obtained based on multiple regression method, respectively.
\end{abstract}

Keywords: Lateral nozzle; Local wall thinning; SCF; Fatigue analysis; Multiple regression method. 


\section{Introduction}

Carbon steel piping was widely used in gas processing plants, oil refineries, chemical plants, and nuclear power plants. Pressurized piping commonly had the form of straight pipe, elbow, cylindercylinder intersections or tee-junctions, or some combination of these. Their main function was to contain media under pressure and temperature. The aging of piping experienced metal loss due to erosion and corrosion. This metal loss or damage referred to as local area wall thinning in this study was most likely and more severe near the junction or intersection of two piping components. It had been recognized that when material was removed from a vessel in order to accommodate a nozzle, the opening in the vessel promoted increased stresses around the edge of the hole. The stress analysis of such a structure was complex due to the many geometric variables and various possible loading conditions. The stress analysts and designers of intersections had made considerable progress over the years to develop rules and establish relationships for stress concentration and stress distribution, limit and burst pressures. Progress had also been made in the study of fatigue and mechanical damage which led to geometric imperfection such as cracks.

One of the most common approaches was to determine the SCF and fatigue damage of pressure vessel and piping connections based on theoretical, experimental, and FEA. Recently great improvements in computer technology had made FEA a dominant means of analysis. A number of FEA software was available in the market which can address a variety of engineering problems without going into expensive experimental analysis. Kubair and Bhanu-Chandar[1] investigated the effect of the intrinsic inhomogeneity length scale, modulus ratio and the power-law index on the SCF due to a circular hole in functionally graded panels. A parametric study was performed by varying the functional form and the direction of the material property gradation. The results showed that the SCF was reduced when Young's modulus progressively increased away from the hole. The SCF was seen to be most influenced by the power-law index, followed by the variation of the inhomogeneity length scale. The SCF was least affected by the modulus ratio. On the basis of three dimensional finite element analysis, Oadir and Redekop[2] studied SCF of a specific pressurized vessel-nozzle intersection (tee joint) with wall thinning damage. The effect on the SCF of varying the extent of the wall thinning damage tee joints was observed. Finally, a parametric study was conducted in which the SCF was computed for a wide range of tee joints, initially considered undamaged, and then with wall thinning damage. Ji et al.[3] investigated the SCF of isolated elliptical corrosion pits using 3-D finite element analyses. A series of parametric studies of finite element pipe models were conducted. 3-D finite element analysis was computationally intensive, efficient statistically predictive models had been developed based on least squares support vector machine realized in a ubiquitous spreadsheet platform. This approach showed very close predictions of SCF to the numerical findings for elliptical corrosion patterns on buried pipes. Particularly, two typical kernel functions had been adopted to cross validate the excellent performance of the least squares support vector machine method in SCF prediction of corroded pipes. Kharat et al.[4] compared of the different approaches which were done for determining SCF's for various geometries. The experimental data was taken from previous work done by one of the author. Finite element analysis was carried out using ANSYS commercial code for different nozzle diameter. The graph of SCF $\mathrm{v} / \mathrm{s} d / D$ was plotted for different nozzle diameters. To study the effect to stress distribution around nozzle area a case study was carried out by changing the nozzle radius, shell thickness and nozzle by keeping internal pressure constant.

The damage behavior of the corroded engineering pipes is more than that sound pipes. The corroded pipes in the process of work were not only subjected to certain static loading such as internal pressure, but also were subjected to dynamic loading such as start-up and shut-down, rapid temperature fluctuations within a larger range, etc. These industry pipes were under cyclic mechanical loading or thermal cyclic loading, which would result in that the material produced cumulative cyclic plastic strain accumulation of different degrees, namely ratcheting effect. Ratcheting deformation resulted in the decrease of fatigue life of the pipes, or excessive deformation made that the pipes did not work. Zeinoddini and Peykanu[5] compared ratcheting strain of steel tubes with rectangular defect under cyclic axial loading with that of the piping without rectangular defect. The results indicated that the 
effect of rectangular defect on ratcheting strain was very large. Meanwhile, the effect of stress amplitude, wall thinning and material hardening characteristic on ratcheting strain of steel tubes was studied respectively. Miyazaki et al.[6] examined carbon steel pipes with local wall thinning under cyclic pure bending loads to evaluate their low cycle fatigue strength. In load controlled tests on these pipes, ratcheting deformation was observed, and the fatigue strength became lower than that of cracked pipes. The effect of bi-directional loading on the fatigue characteristics of pressurized $90^{\circ}$ piping elbows with local wall thinning was investigated by Balan and Redekop[7]. The results provided extensive new information about the fatigue behavior of piping elbow subject to seismic action. Some researchers had studied low cyclic fatigue of elbows with local wall thinning (Kim et al.[8]; Takahashi et al.[9]). However, the ratcheting behavior of elbows with local wall thinning was not yet clear. A lot of experiments on ratcheting deformation topic of pressurized elbow under cyclic bending focused on the sound elbow. Nakamuraet al.[10] studied ratcheting effect of pressurized elbow subjected to cyclic bending under displacement control. It observed that ratcheting strain of piping affected failure mode and reduced fatigue life. Shi et al [11] studied ratcheting deformation in elbow pipe made of Z2CND18.12N stainless steel with local wall thinning subjected to constant internal pressure and reversed in-plane bending under load control. Three-dimensional elastic-plastic analyses using ANSYS incorporated with Chaboche and Chen-Jiao-Kim kinematic hardening models were carried out to evaluate structural ratcheting behaviors. Chen et al.[12,13] studied respectively the effect of the sizes of local wall thinning on ratcheting behavior of straight pipe and 90 degree elbow.

Zamani et al. ${ }^{[14]}$ studied the failureof drill pipe due to complex loading, combined stresses and different types of vibrations and moreover, the corrosive and erosive behavior of drilling mud that makes the total condition of the well so difficult to analyze. In this paper all metallurgical and mechanical aspects of failure that can occur for a drill pipe, were considered and discussed. And finally, this comprehensive review leaded to a conclusion that categorized the primary sources of drill pipe failure into seven major groups and made some recommendations to avoid them. Mahmoodian and $\mathrm{Li}^{[15]}$ studied the failure of in service oil and gas pipelines which can result in catastrophic consequences. The safe life of corrosion affected steel pipes was investigated. The uncertainties in corrosion sizes and pipe characteristics actuated the residual strength model to be a probabilistic model rather than a deterministic one. Therefore, an analytical reliability-based methodology using first passage probability theory for failure assessment of corrosion affected oil and gas pipelines was presented in this paper. Moreover,sensitivity analysis was also undertaken to identify and evaluated the factors that affected the failure due to the strength loss. Ji et al. ${ }^{[16]}$ examined the performance of large-diameter cast iron pipes using probabilistic analysis, incorporating uncertainties of governing variables. Finite element analysis was first conducted to study the physical mechanism of buried pipes subjected to complex environmental conditions. The deterioration of cast iron pipes due to corrosion was considered on the basis of recent research. The uncertainties of governing variables, such as the physical properties of soil, cast iron, water pressure and corrosion patterns, in pipe failure risk assessment were considered. Using probabilistic physical modelling, the lifetime probability of failure was derived and a time-dependent sensitivity analysiswas presented. The results of this probabilistic physical modelling were compared with cohorts of failure data from two Australian water utilities to examine the underlying trended from both physical modelling and statistical analysis.

In the present work FEA was applied to find the SCF and fatigue damage coefficient of the lateral nozzle for both undamaged and damaged components due to corrosion/erosion. A preliminary fatigue study using FEA was also carried out for both geometries to see the effect of local wall thinning.

\section{Stress analysis}

\subsection{Geometric model}

In this study, geometrical dimensions of lateral nozzle were shown in 


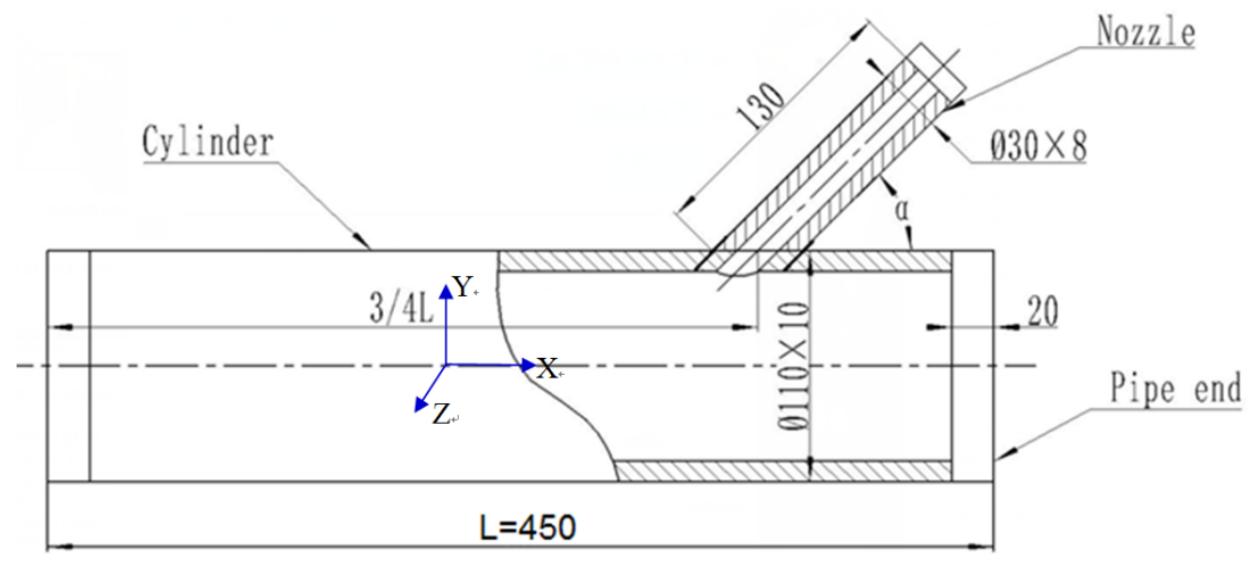

Fig. 1. Outer diameter of the cylinder was $110 \mathrm{~mm}$, its wall thickness was $10 \mathrm{~mm}$ and its length was $450 \mathrm{~mm}$. The nozzle was with $30 \mathrm{~mm}$ in outer diameter, $8 \mathrm{~mm}$ in wall thickness, and $L_{d}=130 \mathrm{~mm}$ in length, was welded with pipe end. The cylinder and nozzle were made of $16 \mathrm{MnR}$, elastic modulus $E=2 \times 10^{5} \mathrm{MPa}$, poisson's ratio $\mu=0.3$.

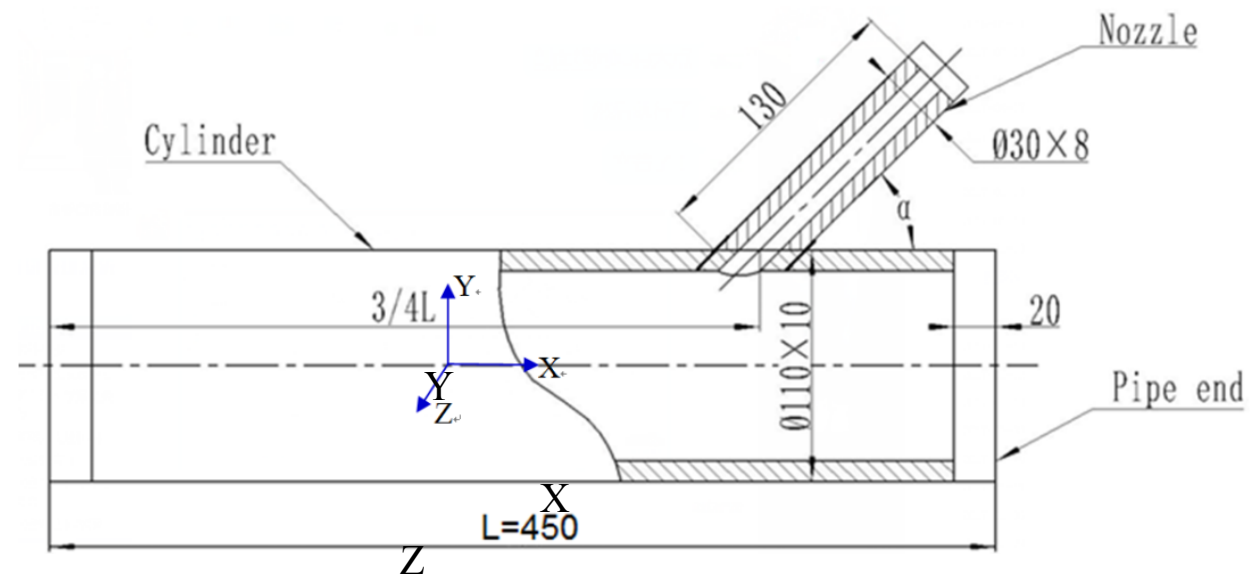

Fig. 1 Schematic diagram of geometrical dimensions

\subsection{Finite element model}

\subsubsection{Stress analysis of lateral nozzle without local wall thinning}

According to the symmetry of geometric dimension and loading condition, $1 / 2$ model was built by finite element software ANSYS, as shown in Fig. 2(a). Element type Solid Brick 20 node 95 was used in this study. Fig. 2(b) gave constraints and internal pressure. Internal pressure was applied to the inner surface of the structure. Freedom constraints in the y direction were applied at the central point of one pipe end. The central point of the other pipe end was confined by X and Y direction freedom. The central point of pipe end of the nozzle was confined by axis direction freedom. 


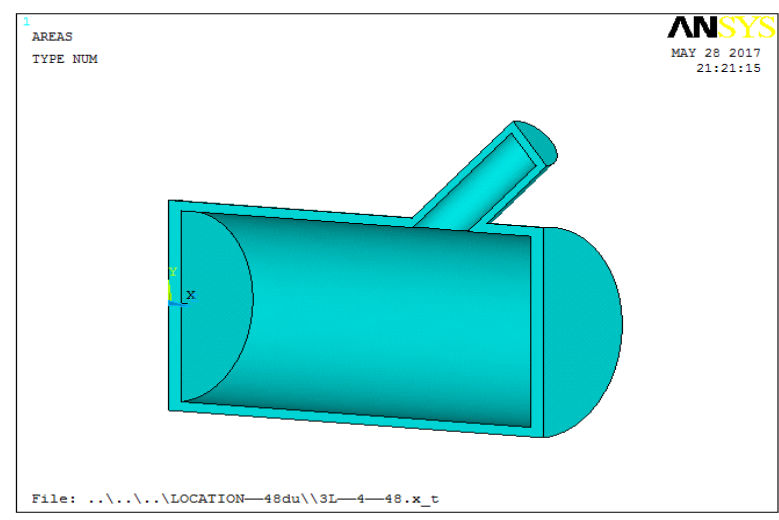

(a)

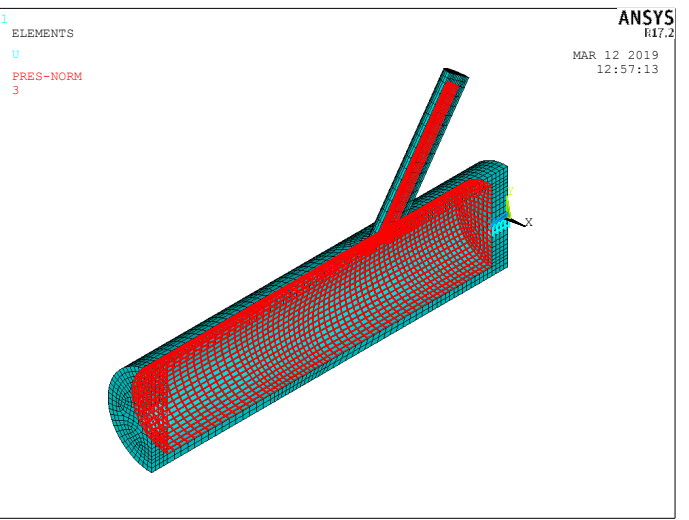

(b)

Fig. 2 Finite element model

Stress analysis results of lateral nozzle without local wall thinning under internal pressure 3MPa were given in Fig. 3. The maximum Mises stress occurred at the acute angle between the intersection of the cylinder and nozzle. Hoop stress at maximum position was $\sigma_{\theta}=116.83 \mathrm{MPa}$.

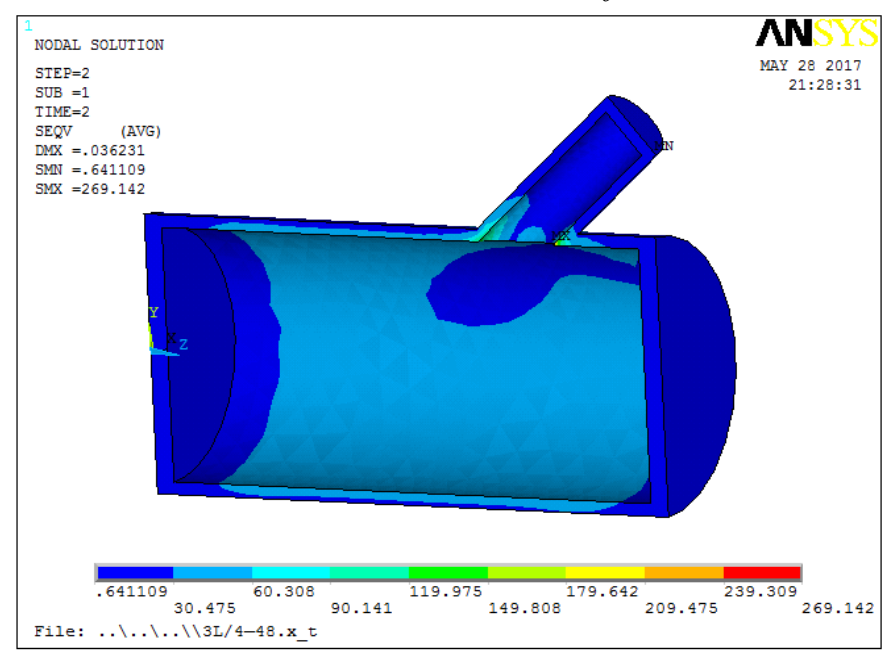

Fig. 3 Mises stress contour

2.2.2 Stress analysis of lateral nozzle with local wall thinning

Fig. 4 gave finite element model of lateral nozzle which was with $L=25 \mathrm{~mm}$ in defect length, $H=4.8 \mathrm{~mm}$ in defect depth, $B=28^{\circ}$ in defect width, and the angle $\alpha$ between the cylinder and nozzle was $48^{\circ}$. The maximum Mises stress occurred at the acute angle between the intersection of the cylinder and nozzle, as shown in Fig. 5. Hoop stress $\sigma_{\theta}$ of lateral nozzle with local wall thinning was extracted in FEA, in order to calculate SCF which equalled the ratio of hoop stress $\sigma_{\theta}$ of lateral nozzle without local wall thinning and that of lateral nozzle with local wall thinning $\sigma_{w \theta}$. 


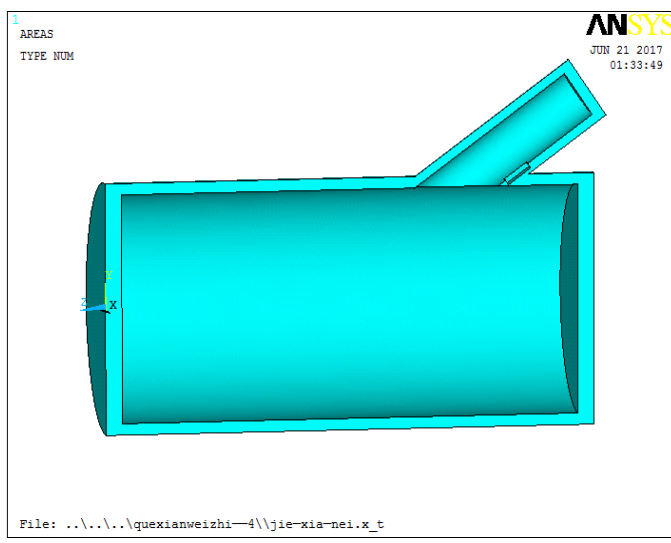

Fig. 4 Finite element model of lateral nozzle with local wall thinning.

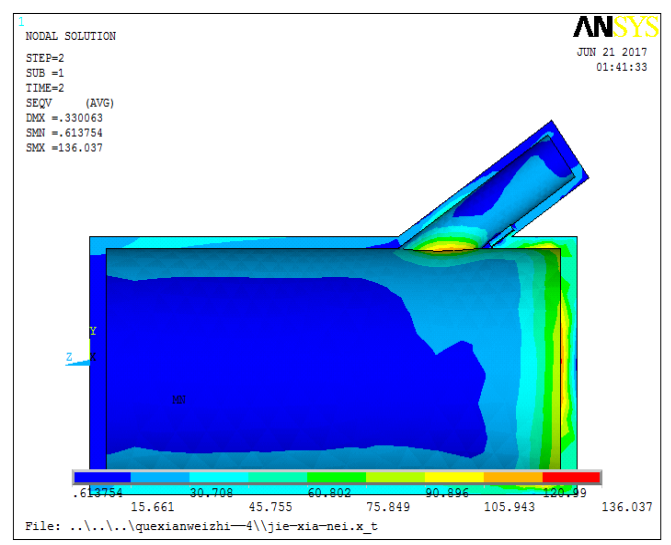

Fig. 5 Stress contour of lateral nozzle with local wall thinning.

\subsection{Effect of local wall thinning on stress distribution of lateral nozzle}

In order to determine the relationship between SCF and main geometric parameters of lateral nozzle with local wall thinning, orthogonal design method was used to calculate schematic design. Defect length $L=10 \mathrm{~mm}, 25 \mathrm{~mm}$ and $45 \mathrm{~mm}$, defect depth $H=1.5 \mathrm{~mm}, 4.8 \mathrm{~mm}$ and $6.3 \mathrm{~mm}$, defect width $B=10^{\circ}$, $28^{\circ}$ and $40^{\circ}$. The angle $\alpha$ between the cylinder and nozzle was $35^{\circ}, 42^{\circ}$ and $70^{\circ}$, respectively. For convenience of calculations, geometry parameters of defect sizes and straight pipe were expressed as dimensionless forms, namely $L / L_{d}, H / t, B / 90^{\circ}$ and $\alpha / 90^{\circ}$. Orthogonal table $L 9\left(3^{4}\right)$ was arranged in this study, each factor has three "levels", as listed in Table 1 . Table 2 gave all orthogonal analysis data.

Table 1 Experimental design with four factors and three levels per factor.

\begin{tabular}{ccccc}
\hline Levels $\backslash$ Factors & $L / L_{d}$ & $H / t$ & $B / 90^{\circ}$ & $\alpha / 90^{\circ}$ \\
\hline 1 & 0.0769 & 0.1875 & 0.11 & 0.39 \\
2 & 0.1923 & 0.6 & 0.31 & 0.58 \\
3 & 0.3462 & 0.7875 & 0.44 & 0.78 \\
\hline
\end{tabular}

Table 2 Orthogonal analysis data

\begin{tabular}{cccccccccc}
\hline NO. & $L / L_{d}$ & $H / t$ & $B / 90^{\circ}$ & $\alpha / 90^{\circ}$ & No. & $L / L_{d}$ & $H / t$ & $B / 90^{\circ}$ & $\alpha / 90^{\circ}$ \\
\hline $1-1$ & $1(0.0769)$ & $1(0.1875)$ & $1(0.11)$ & $1(0.39)$ & $14-3$ & $2(0.1923)$ & $2(0.7875)$ & $2(0.31)$ & $3(0.78)$ \\
$1-2$ & $1(0.0769)$ & $1(0.1875)$ & $1(0.11)$ & $2(0.58)$ & $15-1$ & $2(0.1923)$ & $2(0.7875)$ & $3(0.44)$ & $1(0.39)$ \\
$1-3$ & $1(0.0769)$ & $1(0.1875)$ & $1(0.11)$ & $3(0.78)$ & $15-2$ & $2(0.1923)$ & $2(0.7875)$ & $3(0.44)$ & $2(0.58)$ \\
$2-1$ & $1(0.0769)$ & $1(0.1875)$ & $2(0.31)$ & $1(0.39)$ & $15-3$ & $2(0.1923)$ & $2(0.7875)$ & $3(0.44)$ & $3(0.78)$ \\
$2-2$ & $1(0.0769)$ & $1(0.1875)$ & $2(0.31)$ & $2(0.58)$ & $16-1$ & $2(0.1923)$ & $3(0.78753)$ & $1(0.11)$ & $1(0.39)$ \\
$2-3$ & $1(0.0769)$ & $1(0.1875)$ & $2(0.31)$ & $3(0.78)$ & $16-2$ & $2(0.1923)$ & $3(0.78753)$ & $1(0.11)$ & $2(0.58)$ \\
$3-1$ & $1(0.0769)$ & $1(0.1875)$ & $3(0.44)$ & $1(0.39)$ & $16-3$ & $2(0.1923)$ & $3(0.78753)$ & $1(0.11)$ & $3(0.78)$ \\
$3-2$ & $1(0.0769)$ & $1(0.1875)$ & $3(0.44)$ & $2(0.58)$ & $17-1$ & $2(0.1923)$ & $3(0.78753)$ & $2(0.31)$ & $1(0.39)$ \\
$3-3$ & $1(0.0769)$ & $1(0.1875)$ & $3(0.44)$ & $3(0.78)$ & $17-2$ & $2(0.1923)$ & $3(0.78753)$ & $2(0.31)$ & $2(0.58)$ \\
$4-1$ & $1(0.0769)$ & $2(0.7875)$ & $1(0.11)$ & $1(0.39)$ & $17-3$ & $2(0.1923)$ & $3(0.78753)$ & $2(0.31)$ & $3(0.78)$ \\
$4-2$ & $1(0.0769)$ & $2(0.7875)$ & $1(0.11)$ & $2(0.58)$ & $18-1$ & $2(0.1923)$ & $3(0.78753)$ & $3(0.44)$ & $1(0.39)$ \\
$4-3$ & $1(0.0769)$ & $2(0.7875)$ & $1(0.11)$ & $3(0.78)$ & $18-2$ & $2(0.1923)$ & $3(0.78753)$ & $3(0.44)$ & $2(0.58)$ \\
$5-1$ & $1(0.0769)$ & $2(0.7875)$ & $2(0.31)$ & $1(0.39)$ & $18-3$ & $2(0.1923)$ & $3(0.78753)$ & $3(0.44)$ & $3(0.78)$ \\
\hline
\end{tabular}




\begin{tabular}{|c|c|c|c|c|c|c|c|c|c|}
\hline $5-2$ & $1(0.0769)$ & $2(0.7875)$ & $2(0.31)$ & $2(0.58)$ & $19-1$ & $3(0.3462)$ & $1(0.1875)$ & $1(0.11)$ & $1(0.39)$ \\
\hline $5-3$ & $1(0.0769)$ & $2(0.7875)$ & $2(0.31)$ & $3(0.78)$ & $19-2$ & $3(0.3462)$ & $1(0.1875)$ & $1(0.11)$ & $2(0.58)$ \\
\hline $6-1$ & $1(0.0769)$ & $2(0.7875)$ & $3(0.44)$ & $1(0.39)$ & $19-3$ & $3(0.3462)$ & $1(0.1875)$ & $1(0.11)$ & $3(0.78)$ \\
\hline $6-2$ & $1(0.0769)$ & $2(0.7875)$ & $3(0.44)$ & $2(0.58)$ & $20-1$ & $3(0.3462)$ & $1(0.1875)$ & $2(0.31)$ & $1(0.39)$ \\
\hline $6-3$ & $1(0.0769)$ & $2(0.7875)$ & $3(0.44)$ & $3(0.78)$ & $20-2$ & $3(0.3462)$ & $1(0.1875)$ & $2(0.31)$ & $2(0.58)$ \\
\hline $7-1$ & $1(0.0769)$ & $3(0.7875)$ & $1(0.11)$ & $1(0.39)$ & $20-3$ & $3(0.3462)$ & $1(0.1875)$ & $2(0.31)$ & $3(0.78)$ \\
\hline $7-2$ & $1(0.0769)$ & $3(0.7875)$ & $1(0.11)$ & $2(0.58)$ & $21-1$ & $3(0.3462)$ & $1(0.1875)$ & $3(0.44)$ & $1(0.39)$ \\
\hline $7-3$ & $1(0.0769)$ & $3(0.7875)$ & $1(0.11)$ & $3(0.78)$ & $21-2$ & $3(0.3462)$ & $1(0.1875)$ & $3(0.44)$ & $2(0.58)$ \\
\hline $8-1$ & $1(0.0769)$ & $3(0.7875)$ & $2(0.31)$ & $1(0.39)$ & $21-3$ & $3(0.3462)$ & $1(0.1875)$ & $3(0.44)$ & $3(0.78)$ \\
\hline $8-2$ & $1(0.0769)$ & $3(0.7875)$ & $2(0.31)$ & $2(0.58)$ & $22-1$ & $3(0.3462)$ & $2(0.7875)$ & $1(0.11)$ & $1(0.39)$ \\
\hline $8-3$ & $1(0.0769)$ & $3(0.7875)$ & $2(0.31)$ & $3(0.78)$ & $22-2$ & $3(0.3462)$ & $2(0.7875)$ & $1(0.11)$ & $2(0.58)$ \\
\hline $9-1$ & $1(0.0769)$ & $3(0.7$ & $3(0.44)$ & $1(0.39)$ & $22-3$ & $3(0.3462)$ & 75) & $1(0.11)$ & $3(0.78)$ \\
\hline $9-2$ & $1(0.0769)$ & $3(0.7875)$ & $3(0.44)$ & $2(0.58)$ & $23-1$ & $3(0.3462)$ & $2(0.7875)$ & $2(0.31)$ & $1(0.39)$ \\
\hline $9-3$ & $1(0.0769)$ & $3(0.7875)$ & $3(0.44)$ & $3(0.78)$ & $23-2$ & $3(0.3462)$ & $2(0.7875)$ & $2(0.31)$ & $2(0.58)$ \\
\hline $10-1$ & $2(0.1923)$ & $1(0.1875)$ & $1(0.11)$ & $1(0.39)$ & $23-3$ & $3(0.3462)$ & $2(0.7875)$ & $2(0.31)$ & $3(0.78)$ \\
\hline $10-2$ & $2(0.1923)$ & $1(0.1875)$ & $1(0.11)$ & $2(0.58)$ & $24-1$ & $3(0.3462)$ & $2(0.7875)$ & $3(0.44)$ & $1(0.39)$ \\
\hline $10-3$ & $2(0.1923)$ & $1(0.1875)$ & $1(0.11)$ & $3(0.78)$ & $24-2$ & $3(0.3462)$ & $2(0.7875)$ & $3(0.44)$ & $2(0.58)$ \\
\hline $11-1$ & $2(0.1923)$ & $1(0.1875)$ & $2(0.31)$ & $1(0.39)$ & $24-3$ & $3(0.3462)$ & $2(0.7875)$ & $3(0.44)$ & $3(0.78)$ \\
\hline $11-2$ & $2(0.1923)$ & $1(0.1875)$ & $2(0.31)$ & $2(0.58)$ & $25-1$ & $3(0.3462)$ & $3(0.78753)$ & $1(0.11)$ & $1(0.39)$ \\
\hline $11-3$ & $2(0.1923)$ & $1(0.1875)$ & $2(0.31)$ & $3(0.78)$ & $25-2$ & $3(0.3462)$ & $3(0.78753)$ & $1(0.11)$ & $2(0.58)$ \\
\hline $12-1$ & $2(0.1923)$ & $1(0.1875)$ & $3(0.44)$ & $1(0.39)$ & $25-3$ & $3(0.3462)$ & $3(0.78753)$ & $1(0.11)$ & $3(0.78)$ \\
\hline $12-2$ & $2(0.1923)$ & $1(0.1875)$ & $3(0.44)$ & $2(0.58)$ & $26-1$ & $3(0.3462)$ & $3(0.78753)$ & $2(0.31)$ & $1(0.39)$ \\
\hline $12-3$ & $2(0.1923)$ & $1(0.1875)$ & $3(0.44)$ & $3(0.78)$ & $26-2$ & $3(0.3462)$ & $3(0.78753)$ & $2(0.31)$ & $2(0.58)$ \\
\hline $13-1$ & $2(0.1923)$ & $2(0.7875)$ & $1(0.11)$ & $1(0.39)$ & $26-3$ & $3(0.3462)$ & $3(0.78753)$ & $2(0.31)$ & $3(0.78)$ \\
\hline $13-2$ & $2(0.1923)$ & $2(0.7875)$ & $1(0.11)$ & $2(0.58)$ & $27-1$ & $3(0.3462)$ & $3(0.78753)$ & $3(0.44)$ & $1(0.39)$ \\
\hline $13-3$ & $2(0.1923)$ & $2(0.7875)$ & $1(0.11)$ & $3(0.78)$ & $27-2$ & $3(0.3462)$ & $3(0.78753)$ & $3(0.44)$ & $2(0.58)$ \\
\hline $14-1$ & $2(0.1923)$ & $2(0.7875)$ & $2(0.31)$ & $1(0.39)$ & $27-3$ & $3(0.3462)$ & $3(0.78753)$ & $3(0.44)$ & $3(0.78)$ \\
\hline $14-2$ & $2(0.1923)$ & $2(0.7875)$ & $2(0.31)$ & $2(0.58)$ & & & & & \\
\hline
\end{tabular}

According to different geometric dimensions of the local wall thinning in Table 2, Table 3 gave hoop stress and SCF of lateral nozzle with local wall thinning.

Table 3 Hoop stress and SCF

\begin{tabular}{ccccccccc}
\hline No. & $\sigma_{\mathrm{d} \theta}$ & $\sigma_{\mathrm{d} \theta} / \sigma_{\theta}$ & No. & $\sigma_{\mathrm{d} \theta}$ & $\sigma_{\mathrm{d} \theta} / \sigma_{\theta}$ & No. & $\sigma_{\mathrm{d} \theta}$ & $\sigma_{\mathrm{d} \theta} / \sigma_{\theta}$ \\
\hline $1-1$ & 347.23 & 2.972 & $10-1$ & 376.9 & 3.226 & $19-1$ & 373.76 & 3.199 \\
$1-2$ & 210.66 & 1.803 & $10-2$ & 294.8 & 2.523 & $19-2$ & 287.75 & 2.463 \\
$1-3$ & 134.37 & 1.150 & $10-3$ & 155.6 & 1.332 & $19-3$ & 152.94 & 1.309 \\
$2-1$ & 338.98 & 2.901 & $11-1$ & 367.8 & 3.148 & $20-1$ & 390.15 & 3.339 \\
$2-2$ & 250.55 & 2.145 & $11-2$ & 285.2 & 2.441 & $20-2$ & 284.79 & 2.438 \\
$2-3$ & 133.68 & 1.144 & $11-3$ & 155.5 & 1.331 & $20-3$ & 152.17 & 1.302 \\
$3-1$ & 340.11 & 2.911 & $12-1$ & 382.7 & 3.275 & $21-1$ & 379.26 & 3.246
\end{tabular}




\begin{tabular}{|c|c|c|c|c|c|c|c|c|}
\hline $3-2$ & 254.6 & 2.179 & $12-2$ & 288.6 & 2.470 & $21-2$ & 289.68 & 2.480 \\
\hline $3-3$ & 136.99 & 1.173 & $12-3$ & 150.1 & 1.285 & $21-3$ & 149.52 & 1.280 \\
\hline $4-1$ & 347.29 & 2.973 & $13-1$ & 371.6 & 3.181 & $22-1$ & 377.44 & 3.231 \\
\hline $4-2$ & 258.6 & 2.213 & $13-2$ & 291.8 & 2.497 & $22-2$ & 289.83 & 2.481 \\
\hline $4-3$ & 134.55 & 1.152 & $13-3$ & 149.6 & 1.280 & $22-3$ & 149.64 & 1.281 \\
\hline $5-1$ & 348.32 & 2.981 & $14-1$ & 387.5 & 3.317 & $23-1$ & 389.73 & 3.336 \\
\hline $5-2$ & 250.93 & 2.148 & $14-2$ & 278.3 & 2.382 & $23-2$ & 302.08 & 2.586 \\
\hline $5-3$ & 137.68 & 1.178 & $14-3$ & 148.9 & 1.275 & $23-3$ & 150.51 & 1.288 \\
\hline $6-1$ & 344.59 & 2.949 & $15-1$ & 379.2 & 3.246 & $24-1$ & 373.76 & 3.499 \\
\hline $6-2$ & 253.73 & 2.172 & $15-2$ & 288.9 & 2.473 & $24-2$ & 287.75 & 2.480 \\
\hline $6-3$ & 137.69 & 1.179 & $15-3$ & 149 & 1.276 & $24-3$ & 152.94 & 1.299 \\
\hline $7-1$ & 347.51 & 2.974 & $16-1$ & 380.6 & 3.257 & $25-1$ & 390.15 & 3.304 \\
\hline $7-2$ & 256.37 & 2.194 & $16-2$ & 284.5 & 2.435 & $25-2$ & 284.79 & 2.505 \\
\hline $7-3$ & 137.32 & 1.175 & $16-3$ & 149.7 & 1.282 & $25-3$ & 152.17 & 1.285 \\
\hline $8-1$ & 378.58 & 3.240 & $17-1$ & 376.4 & 3.222 & $26-1$ & 379.26 & 3.398 \\
\hline $8-2$ & 293 & 2.508 & $17-2$ & 290 & 2.482 & $26-2$ & 289.68 & 2.526 \\
\hline $8-3$ & 148.75 & 1.273 & $17-3$ & 148.7 & 1.273 & $26-3$ & 149.52 & 1.280 \\
\hline $9-1$ & 383.24 & 3.280 & $18-1$ & 389.9 & 3.337 & $27-1$ & 377.44 & 3.496 \\
\hline $9-2$ & 254.61 & 2.179 & $18-2$ & 290.5 & 2.487 & $27-2$ & 289.83 & 2.511 \\
\hline $9-3$ & 157.36 & 1.347 & $18-3$ & 151.5 & 1.296 & $27-3$ & 149.64 & 1.309 \\
\hline
\end{tabular}

\subsubsection{Effect of defect size}

\subsubsection{Effect of defect length}

The effect of defect axial length $L / L_{d}$ on SCF of lateral nozzle with local wall thinning subjected to internal pressure $(\mathrm{P}=3 \mathrm{MPa})$, as shown in Fig.6. It indicated respectively the angles $35^{\circ}, 42^{\circ}$ and $70^{\circ}$ of the cylinder and nozzle interaction. The relationship of hoop and axial stress at maximum stress point and dimensionless defect length $L / L_{d}$ was shown in Fig.6.
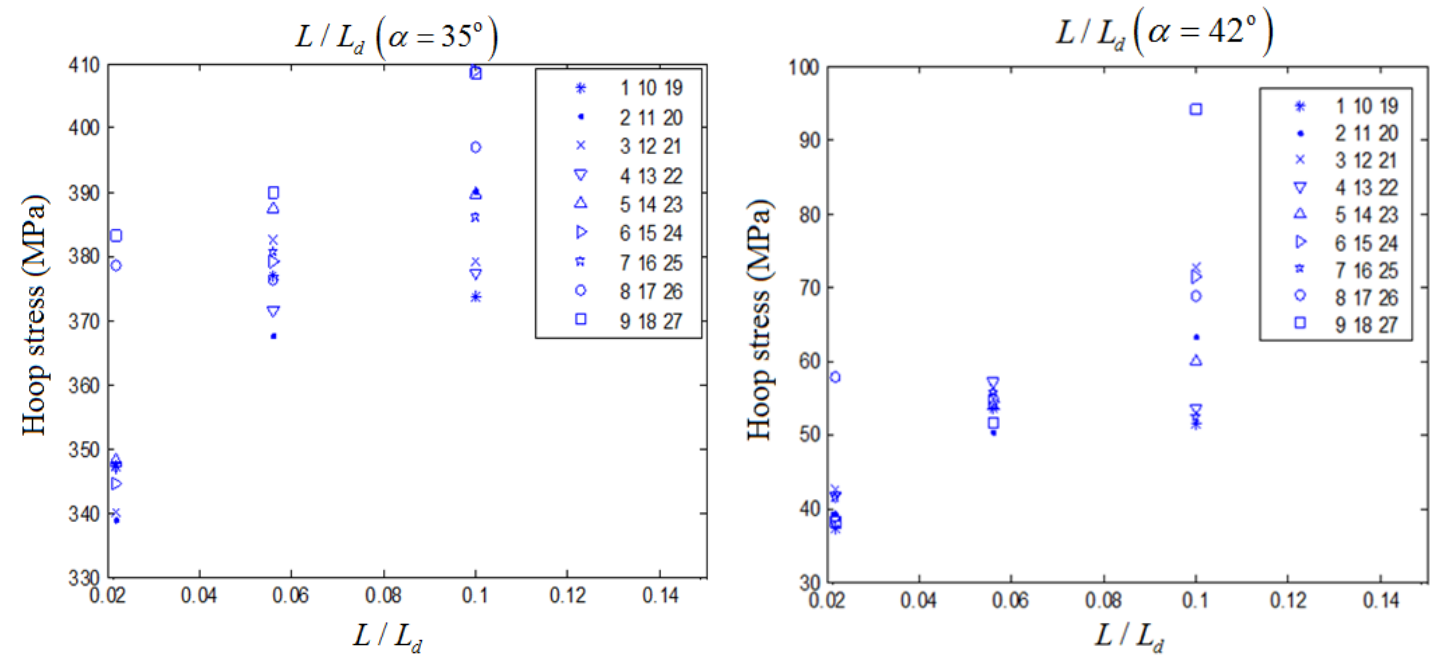
(a)

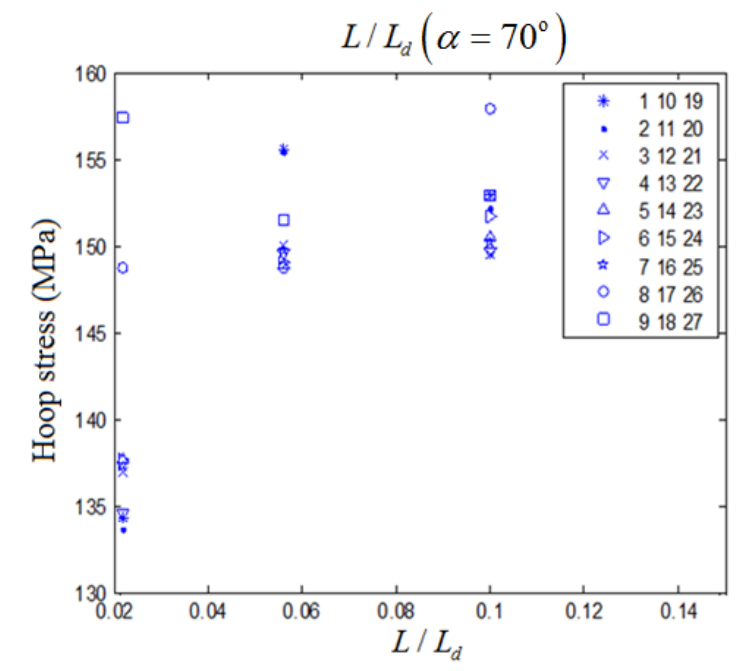

(c)

Fig.6 Effect of defect length on hoop stress of lateral nozzle with local wall thinning

It was shown from Fig. 6 that the relationship of defect axial length and hoop stress was a positive correlation for most models, i.e., the longer defect length $L / L_{d}$ was, the larger hoop stress was. But for some models, the relationship of defect axial length and hoop stress was not simple linear. This phenomenon would be prominent when defect length was relatively smaller. For example, the model No. 1.10.27 (Note: No. 1.10.27 represented No. 1-x, No.10-x and No.27-x in Table 2, $x=1,2,3$ ) was with 0.1875 in non-dimensionless defect depth and 0.11 in defect width, when non-dimensionless defect length increased from 0.0769 to 0.1923 , hoop stress increased with increasing of defect length. But when non-dimensionless defect length increased from 0.1923 to 0.3462 , hoop stress decreased with increasing of defect length. Therefore, this study indicated that the relationship of defect axial length and hoop stress was a positive correlation for larger defect length. For smaller defect length, the relationship of defect axial length and hoop stress was not linear.

\subsubsection{Effect of defect depth}

The cylinder and nozzle interaction with angles $35^{\circ}, 42^{\circ}$ and $70^{\circ}$ was studied respectively. The effect of defect depth $H / t$ on hoop stress and SCF of lateral nozzle with local wall thinning subjected to internal pressure $(\mathrm{P}=3 \mathrm{MPa})$, as shown in Fig. 7. It indicated the relationship of hoop and axial stress at maximum stress point and dimensionless defect depth $H / t$.

It was given in Fig. 7 that the relationship of defect axial length and hoop stress was a positive correlation for most models, i.e., the longer defect depth $\mathrm{H} / \mathrm{t}$ was, the larger hoop stress was. Hoop stress variety for larger defect depth was bigger than that for smaller defect depth. It was shown from Fig.6 and Fig. 7 that the effect of defect depth on hoop stress of lateral nozzle was larger than that of defect length. 


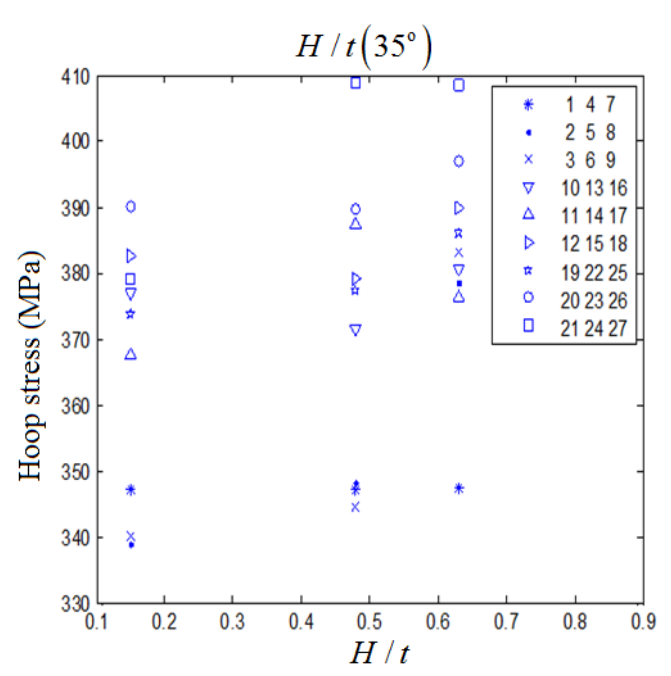

(a)

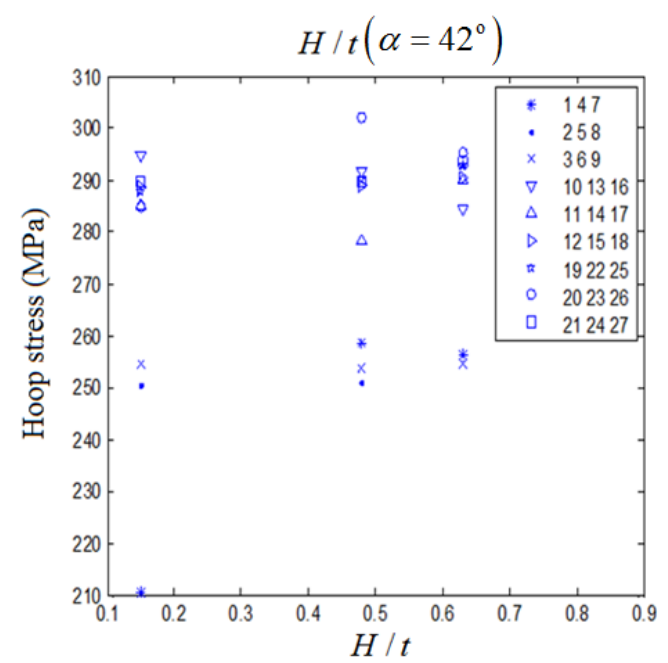

(b)

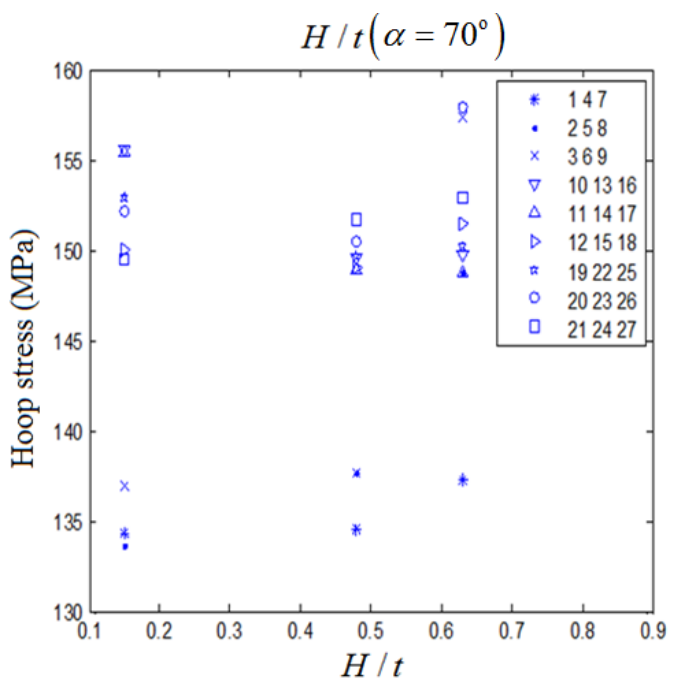

(c)

Fig. 7 Effect of defect depth on hoop stress of lateral nozzle with local wall thinning

\subsubsection{Effect of defect width}

Fig. 8 showed the effect of defect width $B / 90^{\circ}$ on SCF of lateral nozzle with local wall thinning subjected to internal pressure $(P=3 \mathrm{MPa})$. It was found that the relationship of hoop and axial stress at maximum stress point and dimensionless defect width $B / 90^{\circ}$.

It was given in Fig. 8 that the relationship of defect width and hoop stress was a positive correlation when defect width was between 0.11 and 0.31 ; when defect width was between 0.31 and 0.44 , the relationship of defect width and hoop stress was inversely proportional to each other. It was shown from Fig. 6 and Fig. 8 that the effect of defect width on hoop stress of lateral nozzle was larger than that of defect length. 


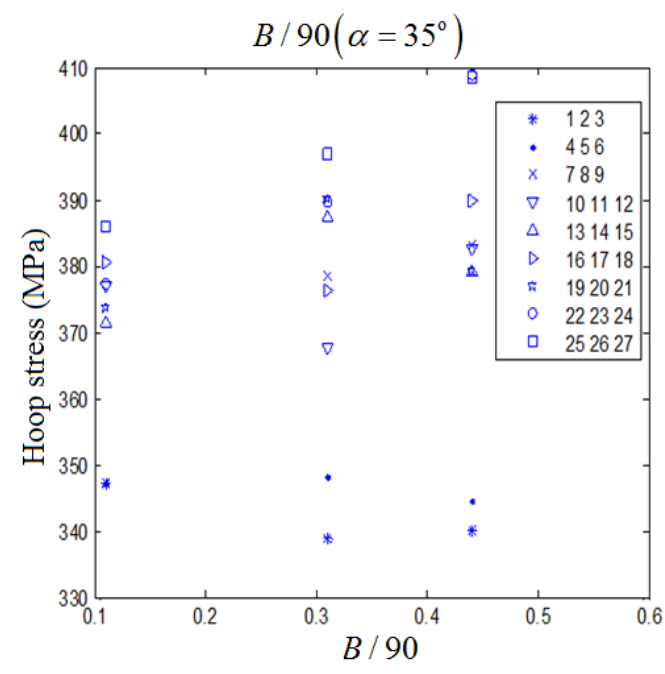

(a)

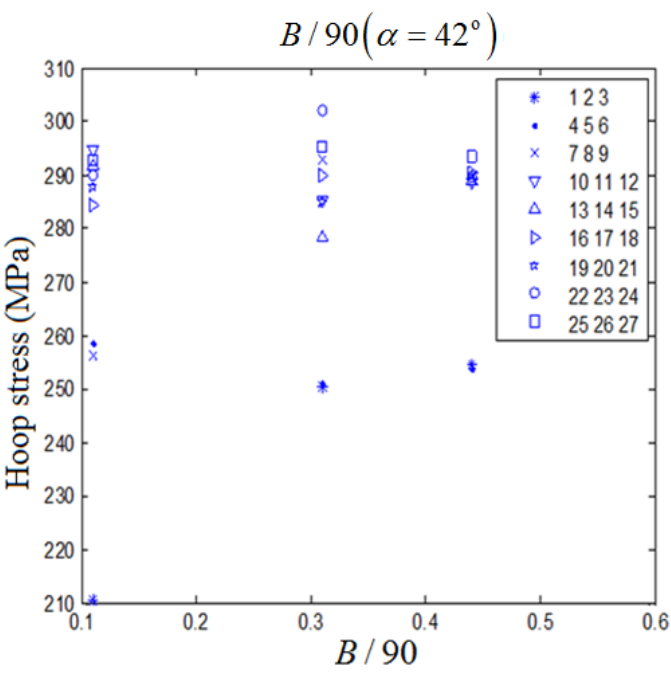

(b)

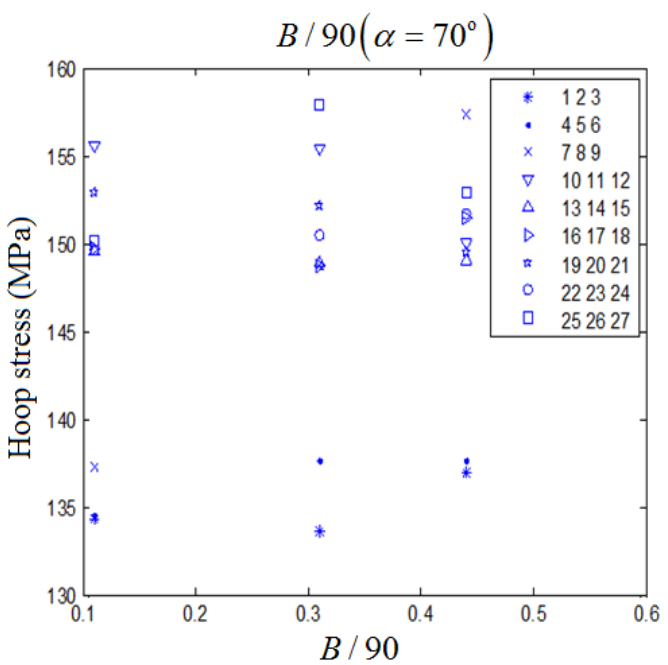

(c)

Fig. 8 Effect of defect width on hoop stress of lateral nozzle with local wall thinning

\subsubsection{Effect of the angle between the axis of the cylinder and that of nozzle}

Fig. 9 gave the effect of the angle $\alpha$ between the cylinder and nozzle on SCF of lateral nozzle with local wall thinning subjected to internal pressure $(\mathrm{P}=3 \mathrm{MPa})$. The relationship of hoop and axial stress at maximum stress point and dimensionless $\alpha / 90^{\circ}$ was shown in Fig. 9. It was shown from Fig. 9 that the relationship of defect axial length and hoop stress was inversely proportional to each other. Hoop stress of lateral nozzle with local wall thinning was not influenced by defect size. The longer angle $\alpha$ was, the smaller hoop stress was. 


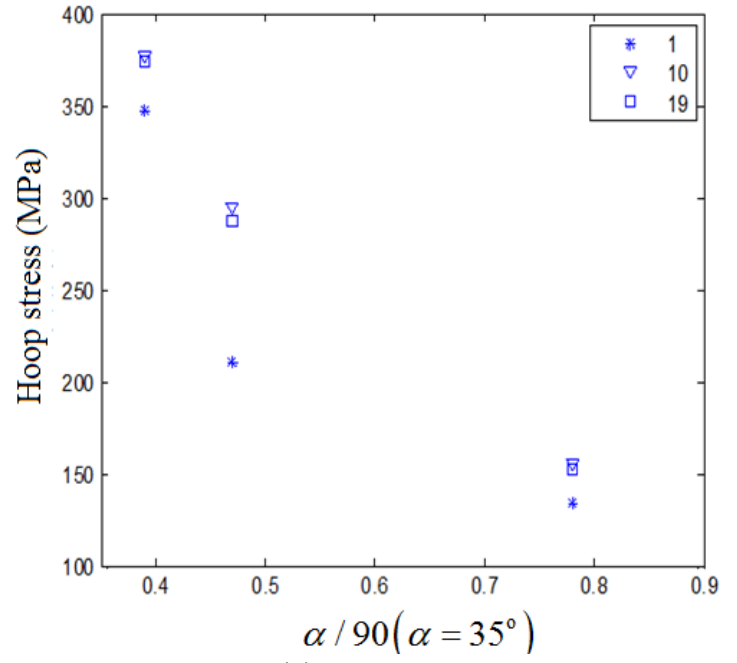

(a)

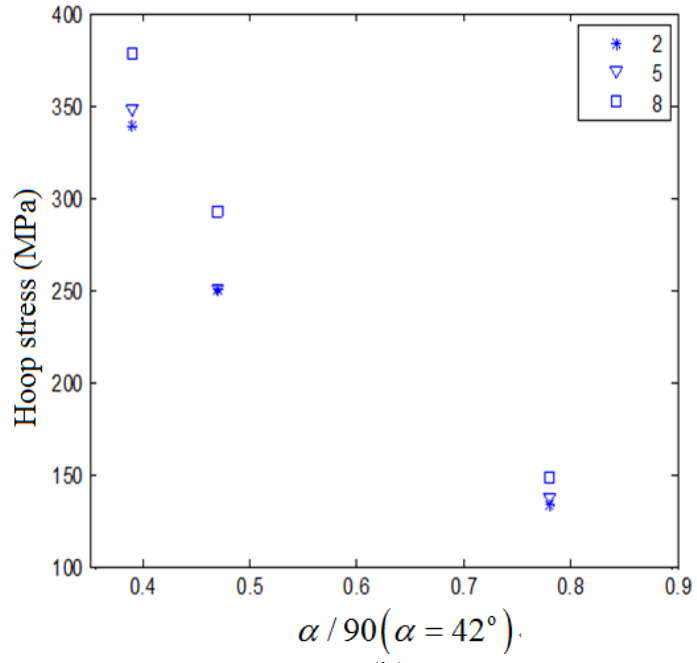

(b)

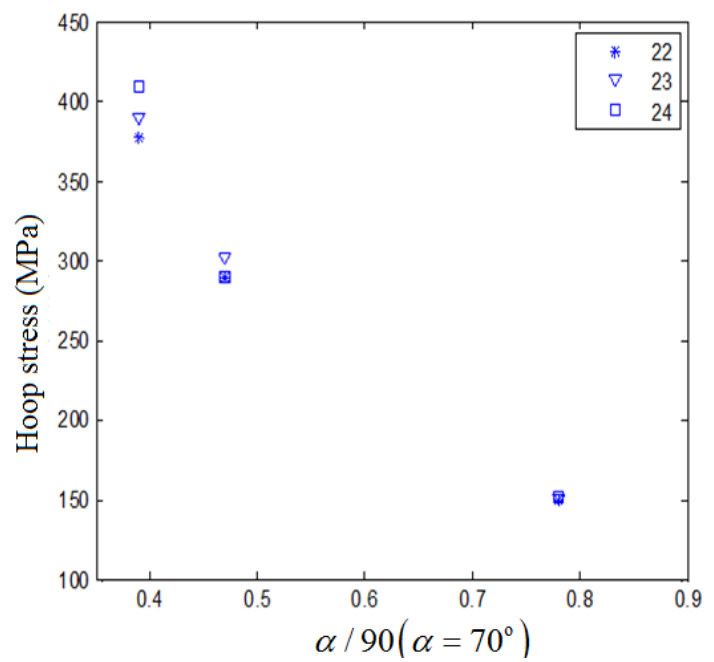

(c)

Fig. 9 Effect of angle between cylinder and nozzle interaction with local wall thinning

\subsection{Multiple Linear Regression}

In order to obtain the relationship of SCF and geometric dimensions of pressurized lateral nozzle with local wall thinning, dimensionless relations were assumed as follows.

$$
\frac{\sigma_{\theta}}{\sigma_{d \theta}}=\lambda_{1}\left(\frac{\alpha}{90^{\circ}}\right)^{\varsigma_{1}}\left(\frac{L}{L_{\mathrm{d}}}\right)^{\varsigma_{2}}\left(\frac{H}{t}\right)^{\varsigma_{3}}\left(\frac{B}{90^{\circ}}\right)^{\varsigma_{4}}
$$

Taking the logarithm on both sides of Eq.(1) and Eq.(2), provides,

$$
\ln \left(\frac{\sigma_{\theta}}{\sigma_{\mathrm{d} \theta}}\right)=\varsigma_{1} \ln \left(\frac{\alpha}{90^{\circ}}\right)+\varsigma_{2} \ln \left(\frac{L}{L_{\mathrm{d}}}\right)+\varsigma_{3} \ln \left(\frac{H}{t}\right)+\varsigma_{4} \ln \left(\frac{B}{90^{\circ}}\right)+\ln \lambda_{1}
$$

$y_{1}$ represented $\ln \left(\frac{\sigma_{\theta}}{\sigma_{d \theta}}\right) \cdot \varsigma_{0}, \eta_{0}, x_{1}, x_{2}, x_{3}$ and $x_{4}$ denoted respectively $\ln \lambda_{1}, \ln \lambda_{2}, \ln \left(\frac{\alpha}{90^{\circ}}\right)$, $\ln \left(\frac{L}{L_{w}}\right), \ln \left(\frac{H}{t}\right)$ and $\ln \left(\frac{B}{90^{\circ}}\right)$. The general forms of multiple linear regression models were expressed by Eq. (3).

$$
y_{1}=\varsigma_{1} x_{1}+\varsigma_{2} x_{2}+\varsigma_{3} x_{3}+\varsigma_{4} x_{4}+\varsigma_{0}
$$


where, the parameters $\varsigma_{1 \sim 4}$ were regression coefficients, the parameter $\varsigma_{0}$ was random errors. The estimated values were expressed by the parameters $a_{0 \sim 4}$. Regression equation was written as follows.

$$
\hat{y}=a_{1} x_{1}+a_{2} x_{2}+a_{3} x_{3}+a_{4} x_{4}+a_{0}
$$

Regression coefficients and random errors were estimated by the least square method, i.e., when the sum of squared residuals the calculated value and regression value reached the minimum, the estimated values were deeded as the regression coefficients and random errors of regression equation. According to the statistical analysis software (SPSS), the regression results were written in the following.

$$
\frac{\sigma_{\theta}}{\sigma_{d \theta}}=1.178\left(\frac{L}{L_{d}}\right)^{0.074}\left(\frac{H}{t}\right)^{0.021}\left(\frac{B}{90^{\circ}}\right)^{0.017}\left(\frac{\alpha}{90^{\circ}}\right)^{-1.312}
$$

The scope of Eq.(5)was $35^{\circ} \leq \alpha \leq 70^{\circ}, \quad 0.0769 \leq L / L_{d} \leq 0.3462, \quad 0.1875 \leq H / t \leq 0.7875$, $0.39 \leq B / 90^{\circ} \leq 0.78$.

Regression coefficient and random error were estimated by least square method, i.e., when the residual square sum of the calculated results and regression results achieved minimum, the regression values were treated as the regression coefficient and random error of regression relations.

SPSS software was used to regress data in Table 3. The results were shown in Tables 4-6. Tables 4-6 listed the regression results of Eq.(5). The determination coefficient of the regression equation was characterized by the model matrix. The statistic $R^{2}$ indicated the effect of the model on the independent variable. If the $R^{2}$ far was less than one, the fitting effect of the specimen was the better. The $R^{2}$ of the specimen were 0.987 , respectively. This showed that the simulation of the model was close to its actual situation. Anova included the degree of freedom, mean square, square sum significance, and the corresponding $F$ value of the multivariate linear regression model. These were the results of the remarkable $F$ test of the model, and the smaller the value was, the better the simulation effect was. The $F$ validation value in both models was zero, so the simulation effect of the model was very good. The coefficient table mainly included the estimated value of the regression coefficient without standardization and the estimated value of the standardized regression coefficient, the statistical value of the $t$ test and its corresponding significant value. For the same reason, the smaller the values were, the better the effect of the model simulation was. The table showed that the significant value of the $t$ test of each variable was less than 0.1 . It can be considered that the simulation of the model was feasible and the obtained results were reliable.

Table 4 The model matrix of radial stress model

\begin{tabular}{ccccccc}
\hline Model & \multicolumn{2}{c}{$\mathrm{R}$} & $\mathrm{R}^{2}$ & Adjustment $\mathrm{R}^{2}$ & \multicolumn{2}{c}{ Standard estimate error } \\
\hline \multicolumn{2}{c}{0.994} & & 0.987 & 0.987 & 0.045 \\
\hline \multirow{2}{*}{ Model } & & Square sum & Tf & Average & F & Sig \\
\hline \multirow{2}{*}{1} & Regression & 12.328 & 4 & 3.082 & 1483.74 & 0.000 \\
& Residual & 0.158 & 76 & 0.002 & & \\
\hline
\end{tabular}

Table 6 Coefficient 


\begin{tabular}{|c|c|c|c|c|c|c|}
\hline & & & & & & \\
\hline & & $\mathrm{B}$ & Standard error & Trial edition & & \\
\hline \multirow{5}{*}{1} & (Constant) & 0.167 & 0.031 & -— & 5.382 & 0 \\
\hline & In（L/D） & 0.075 & 0.008 & 0.119 & 9.21 & 0 \\
\hline & In $(H / T)$ & 0.022 & 0.008 & 0.035 & 2.704 & 0.008 \\
\hline & In $(\mathrm{B} / 90)$ & 0.017 & 0.009 & 0.026 & 1.979 & 0.051 \\
\hline & In $(\mathrm{C} / 90)$ & -1.321 & 0.017 & -0.986 & -0.986 & 0 \\
\hline
\end{tabular}

\section{Fatigue analysis}

Fatigue has been recognized as a major failure mode in pressure vessels and specific rules for its prevention appear in design codes. The fatigue process consists of crack initiation, crack propagation, and eventually fracture after a number of cycles. In many design situations expected number of cycles is in millions or infinity by setting the design within endurance limit. However, designing within the endurance limit is not the ultimate safe design because fatigue failure typical occurs at high stress zone. The high stress zones are due to abrupt change in geometry, temperature differential, and or residual stresses. Fatigue has been classified as of high and low cycle. To provide relevant data, a linear FEA approach can be used for the first method and a non-linear FEA approach for the second. Fatigue analysis of finite element software ANSYS was on the basis of ASME III and VIII, and used simplified elastic-plastic hypothesis and Miner cumulative fatigue summation rule. Alternating stress amplitude was determined based on stress analysis, and then allowed cycles were determined according to alternating stress amplitude and design fatigue curve. Finally, fatigue damage coefficient of lateral nozzle was calculated. Fatigue damage coefficient is equal to fatigue damage in the references. A conceptual definition of fatigue damage is proposed to assist in the selection of measurement techniques and parameters for correlating damage with fatigue life. The parameters $D_{s}$ and $D_{s w}$ were respectively fatigue damage coefficient of lateral nozzle with and without local wall thinning and design cycles. If fatigue damage coefficient was less one, fatigue strength of structures was qualified. Fatigue damage coefficient of lateral nozzle with local wall thinning was listed in Table 7. Fatigue strength is that the maximum stress of the fracture is not caused by the repeated alternating load of the metal material/ structure. For fatigue analysis in ANSYS, fatigue loading is one of the stress conditions that is part of an event. An event is a set of stress conditions that occur at different times during a unique stress cycle. 
Table 7 Fatigue damage coefficient

\begin{tabular}{|c|c|c|c|c|c|}
\hline No. & $D_{s}$ & No. & $D_{s}$ & No. & $D_{s}$ \\
\hline $1-1$ & 0.814 & $10-1$ & 0.763 & 19-1 & 0.744 \\
\hline $1-2$ & 0.107 & $10-2$ & 0.254 & $19-2$ & 0.225 \\
\hline $1-3$ & 0.030 & $10-3$ & 0.030 & $19-3$ & 0.030 \\
\hline $2-1$ & 0.759 & $11-1$ & 0.760 & $20-1$ & 0.674 \\
\hline $2-2$ & 0.212 & $11-2$ & 0.222 & $20-2$ & 0.252 \\
\hline $2-3$ & 0.030 & $11-3$ & 0.030 & $20-3$ & 0.030 \\
\hline $3-1$ & 0.769 & $12-1$ & 0.693 & 21-1 & 0.689 \\
\hline $3-2$ & 0.223 & $12-2$ & 0.214 & $21-2$ & 0.231 \\
\hline $3-3$ & 0.030 & $12-3$ & 0.030 & $21-3$ & 0.030 \\
\hline $4-1$ & 0.809 & $13-1$ & 0.748 & $22-1$ & 0.849 \\
\hline $4-2$ & 0.241 & $13-2$ & 0.214 & $22-2$ & 0.232 \\
\hline $4-3$ & 0.030 & $13-3$ & 0.030 & $22-3$ & 0.030 \\
\hline $5-1$ & 0.816 & $14-1$ & 0.684 & $23-1$ & 0.883 \\
\hline $5-2$ & 0.218 & $14-2$ & 0.211 & $23-2$ & 0.236 \\
\hline $5-3$ & 0.030 & $14-3$ & 0.030 & $23-3$ & 0.030 \\
\hline $6-1$ & 0.788 & $15-1$ & 0.804 & $24-1$ & 0.790 \\
\hline $6-2$ & 0.230 & $15-2$ & 0.232 & $24-2$ & 0.286 \\
\hline $6-3$ & 0.030 & $15-3$ & 0.030 & $24-3$ & 0.030 \\
\hline $7-1$ & 0.811 & $16-1$ & 0.685 & $25-1$ & 0.819 \\
\hline $7-2$ & 0.225 & $16-2$ & 0.228 & $25-2$ & 0.240 \\
\hline $7-3$ & 0.030 & $16-3$ & 0.030 & $25-3$ & 0.030 \\
\hline $8-1$ & 0.827 & $17-1$ & 0.793 & $26-1$ & 0.918 \\
\hline $8-2$ & 0.219 & $17-2$ & 0.234 & $26-2$ & 0.281 \\
\hline $8-3$ & 0.030 & $17-3$ & 0.030 & $26-3$ & 0.030 \\
\hline $9-1$ & 0.814 & $18-1$ & 0.703 & $27-1$ & 1.043 \\
\hline $9-2$ & 0.232 & $18-2$ & 0.291 & $27-2$ & 0.294 \\
\hline $9-3$ & 0.030 & $18-3$ & 0.030 & $27-3$ & 0.030 \\
\hline
\end{tabular}

In this study, all models of fatigue analysis of lateral nozzle with local wall thinning were listed in Table 2. Fatigue damage coefficient $D_{s w}$ of lateral nozzle without local wall thinning was 0.03 . The maximum and minimum internal pressures were $3 \mathrm{MPa}$ and $0 \mathrm{MPa}$, respectively. All dimensionless fatigue damage coefficients were listed in Table 8. 
Table 8 Dimensionless fatigue damage coefficient

\begin{tabular}{|c|c|c|c|c|c|}
\hline No. & $D_{s} / D_{s w}$ & No. & $D_{s} / D_{s w}$ & No. & $D_{s} / D_{s w}$ \\
\hline $1-1$ & 27.125 & $10-1$ & 25.43767 & $19-1$ & 24.784 \\
\hline $1-2$ & 3.568333 & $10-2$ & 8.462667 & $19-2$ & 7.494333 \\
\hline $1-3$ & 1 & $10-3$ & 1 & $19-3$ & 1 \\
\hline $2-1$ & 25.314 & $11-1$ & 25.33533 & $20-1$ & 22.47867 \\
\hline $2-2$ & 7.071667 & & 7.396667 & $20-2$ & 8.398667 \\
\hline $2-3$ & 1 & $11-3$ & 1 & $20-3$ & 1 \\
\hline $3-1$ & 25.64633 & $12-1$ & 23.087 & $21-1$ & 22.95767 \\
\hline $3-2$ & 7.429333 & $12-2$ & 7.141 & $21-2$ & 7.712 \\
\hline $3-3$ & 1 & $12-3$ & 1 & $21-3$ & 1 \\
\hline $4-1$ & 26.96267 & $13-1$ & 24.92133 & $22-1$ & 28.29367 \\
\hline $4-2$ & 8.044667 & $13-2$ & 7.147 & $22-2$ & 7.744333 \\
\hline $4-3$ & 1 & $13-3$ & 1 & $22-3$ & 1 \\
\hline $5-1$ & 27.21233 & $14-1$ & 22.81033 & $23-1$ & 29.44367 \\
\hline $5-2$ & 7.280667 & $14-2$ & 7.017 & $23-2$ & 7.869333 \\
\hline $5-3$ & 1 & $14-3$ & 1 & $23-3$ & 1 \\
\hline $6-1$ & 26.27867 & $15-1$ & 26.79467 & $24-1$ & 26.34867 \\
\hline $6-2$ & 7.665333 & $15-2$ & 7.742333 & $24-2$ & 9.546333 \\
\hline $6-3$ & 1 & $15-3$ & 1 & $24-3$ & 1 \\
\hline $7-1$ & 27.03267 & $16-1$ & 22.821 & $25-1$ & 27.307 \\
\hline $7-2$ & 7.504667 & $16-2$ & 7.601 & $25-2$ & 7.988667 \\
\hline $7-3$ & 1 & $16-3$ & 1 & $25-3$ & 1 \\
\hline $8-1$ & 27.557 & $17-1$ & 26.429 & $26-1$ & 30.78750267 \\
\hline $8-2$ & 7.311333 & $17-2$ & 7.803667 & $26-2$ & 9.367333 \\
\hline $8-3$ & 1 & $17-3$ & 1 & $26-3$ & 1 \\
\hline $9-1$ & 27.14667 & $18-1$ & 23.44267 & $27-1$ & 34.75433 \\
\hline $9-2$ & 7.739333 & $18-2$ & 9.690667 & $27-2$ & 9.816 \\
\hline $9-3$ & 1 & $18-3$ & 1 & $27-3$ & 1 \\
\hline
\end{tabular}

3.1 Effect of local wall thinning on fatigue damage coefficient of lateral nozzle with different angles

\subsubsection{Effect of defect size}

\subsubsection{Effect of defect length}

The angles $30^{\circ}, 42^{\circ}$ and $70^{\circ}$ between the cylinder and nozzles were studied respectively. The effect of defect length $L / L_{w}$ on fatigue damage coefficient of lateral nozzle with local wall thinning was given in Fig. 10. It showed the relationship of fatigue damage coefficient and dimensionless defect length $L / L_{w}$. It was shown from Fig. 10 that the relationship of defect axial length and fatigue 
damage coefficient within a certain range was a positive correlation to each other. However, when the angle between the cylinder and nozzles was $70^{\circ}$, fatigue damage coefficient was always 0.03 , nonetheless defect sizes were volatile.

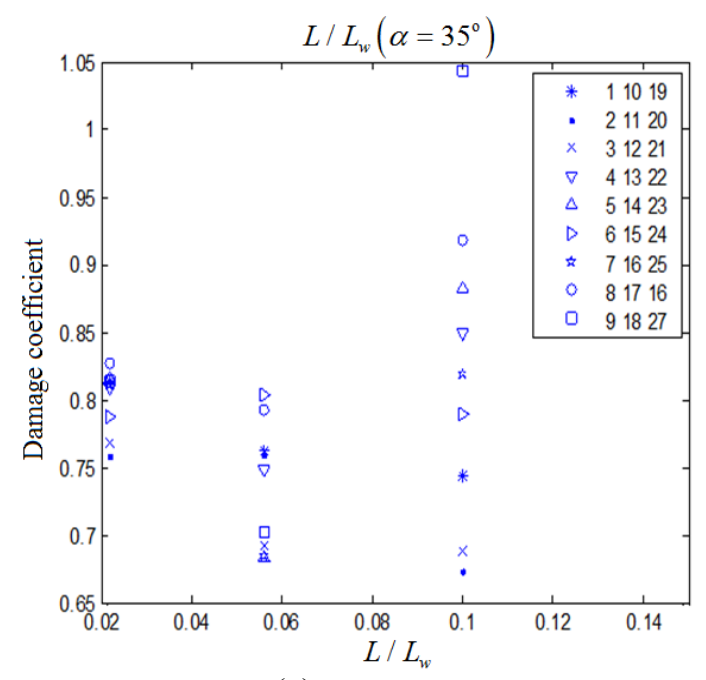

(a)

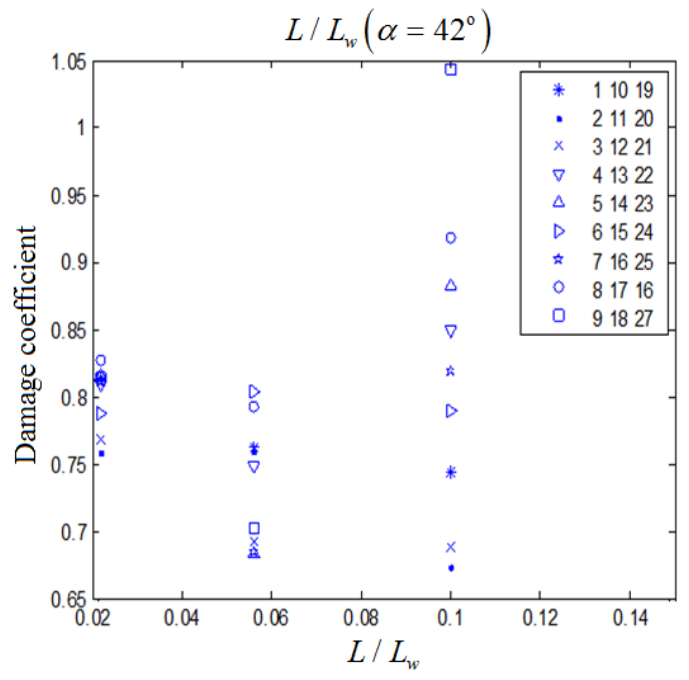

(b)

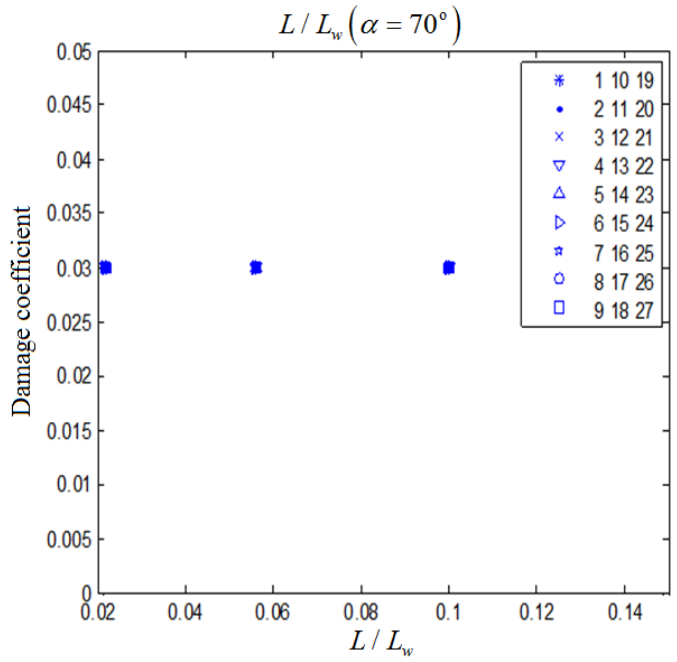

(c)

Fig. 10 Effect of defect length on fatigue damage coefficient

\subsubsection{Effect of defect depth}

The effect of defect depth $H / t$ on fatigue damage coefficient of lateral nozzle with local wall thinning was shown in Fig. 11. It indicated the relationship of fatigue damage coefficient and dimensionless defect depth $H / t$. It was given in Fig. 11 when dimensionless defect depth $H / t$ was between $35^{\circ}$ and $42^{\circ}$, the relationship of defect depth and fatigue damage coefficient within a certain range was a positive correlation to each other. However, when the angle between the cylinder and nozzles was $70^{\circ}$, fatigue damage coefficient was always 0.03 , nonetheless defect sizes were volatile. 


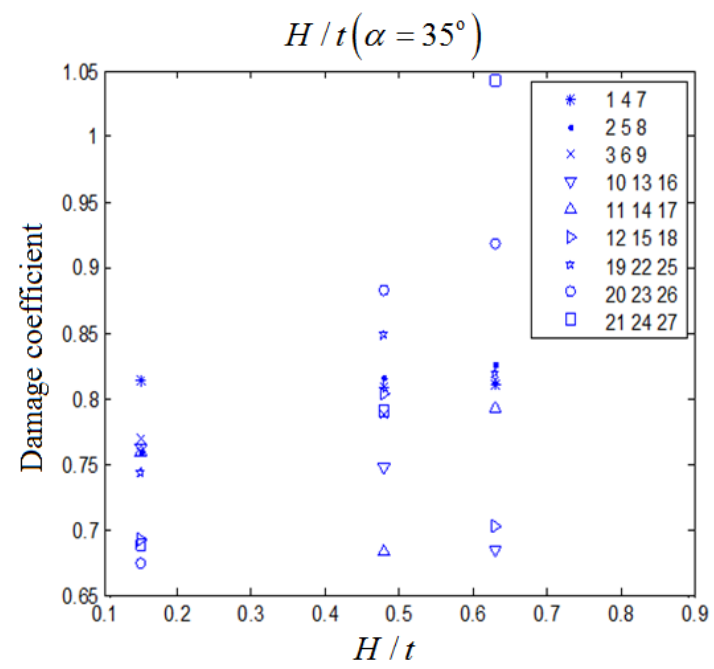

(a)

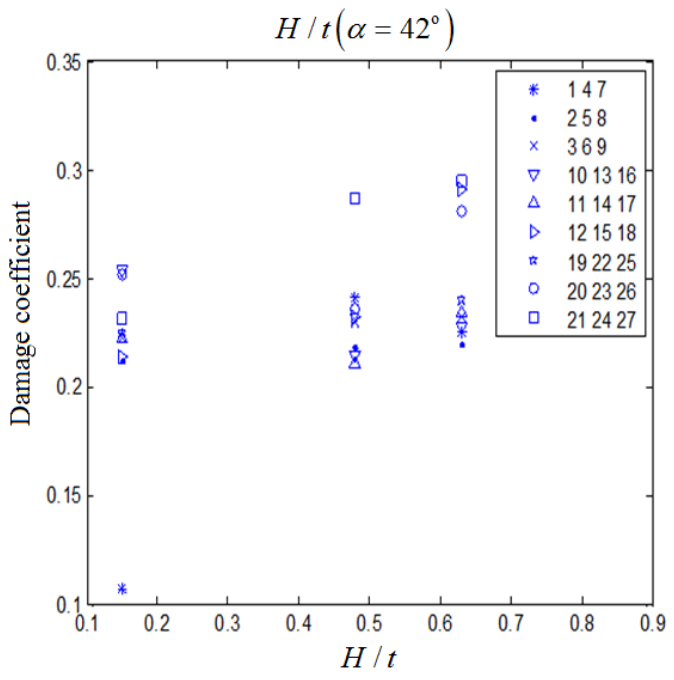

(b)

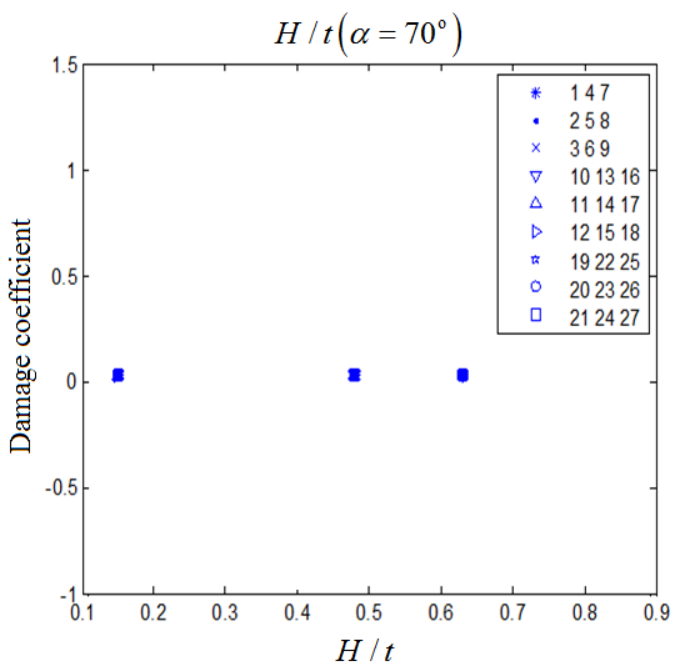

(c)

Fig. 11 Effect of defect depth on fatigue damage coefficient

\subsubsection{Effect of defect width}

Fig. 12 indicated the effect of defect width $B / 90^{\circ}$ on fatigue damage coefficient of lateral nozzle with local wall thinning. It gave the relationship of fatigue damage coefficient and dimensionless defect width $B / 90^{\circ}$. It was shown in Fig. 12 when dimensionless defect width $B / 90^{\circ}$ was between $35^{\circ}$ and $42^{\circ}$, the relationship of defect depth and fatigue damage coefficient within a certain range was a positive correlation to each other. However, when the angle between the cylinder and nozzles was $70^{\circ}$, fatigue damage coefficient was always 0.03 , nonetheless defect sizes were volatile. 


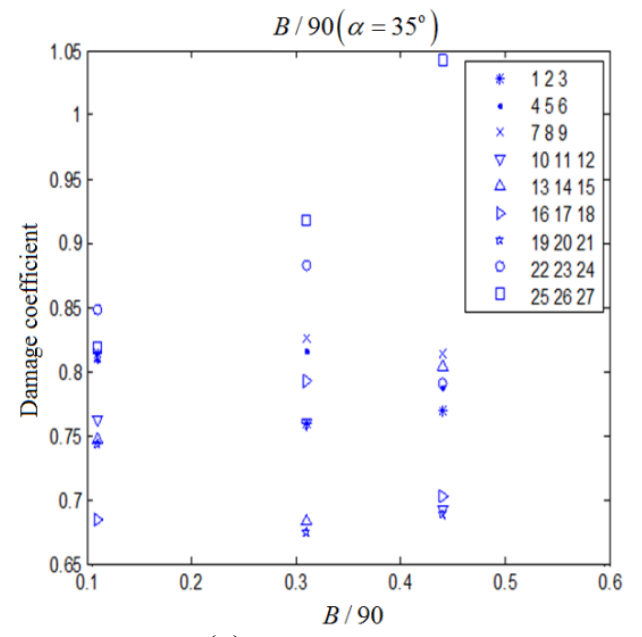

(a)

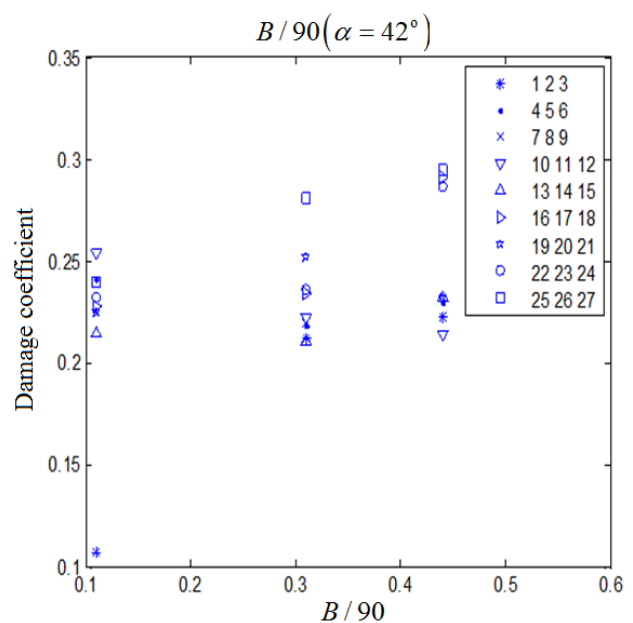

(b)

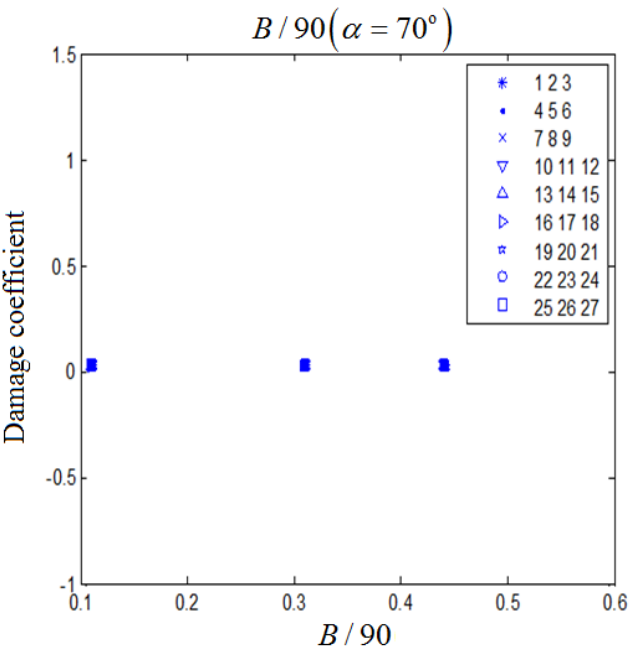

(c)

Fig. 12 Effect of defect width on fatigue damage coefficient

3.1.2 Effect of the angle between the axis of the cylinder and that of nozzle

Fig. 13 indicated the effect of the angle between the cylinder and nozzle on fatigue damage coefficient. It gave the relationship of fatigue damage coefficient and dimensionless defect depth $\alpha / 90$. It was shown in Fig. 13 that fatigue damage coefficient decreased with increasing of the angle between the cylinder and nozzle. The effect defect length on fatigue damage coefficient was larger than other two sizes. In turn, defect length $>$ defect depth $>$ defect width. 


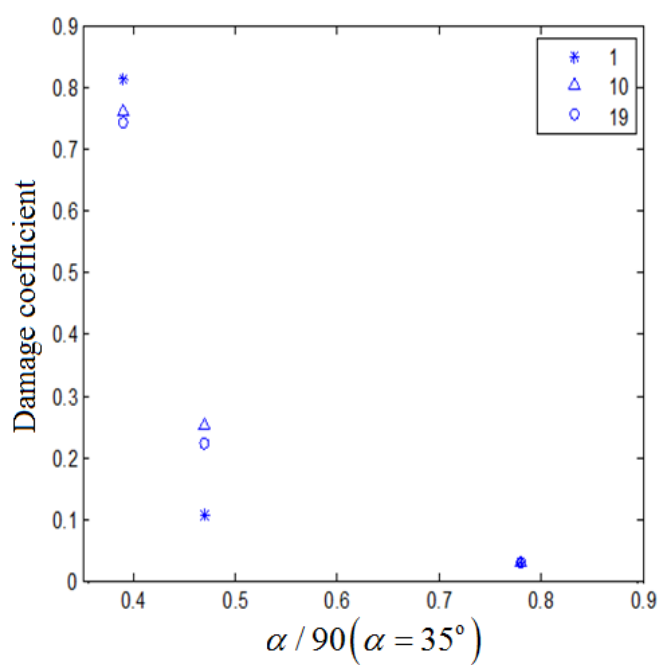

(a)

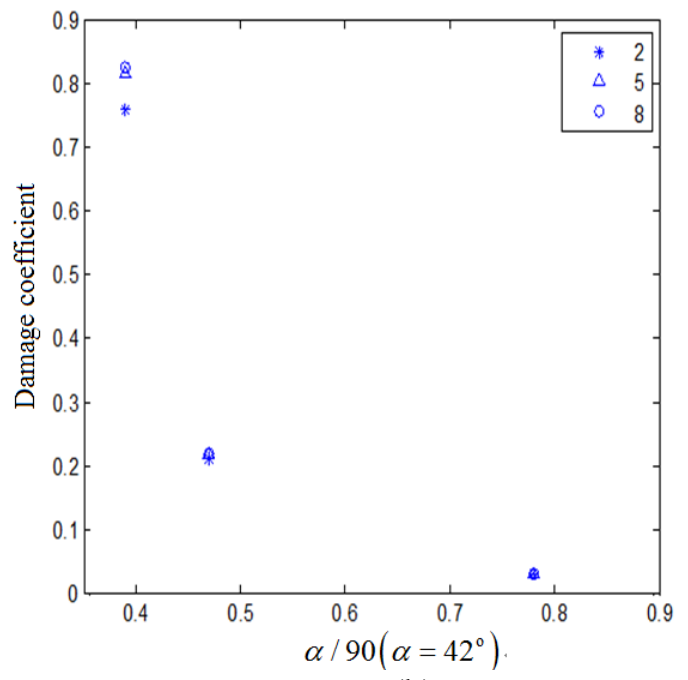

(b)

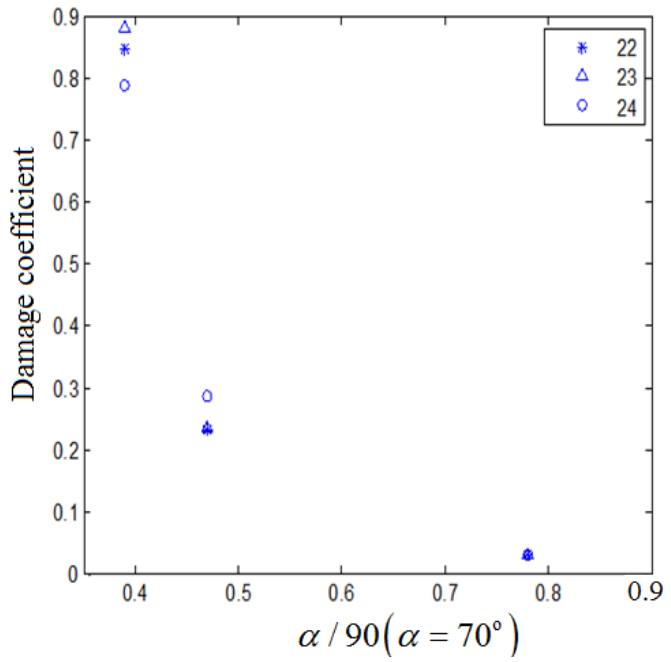

(c)

Fig. 13 Effect of the angle between the cylinder and nozzle on fatigue damage coefficient

\subsection{Multiple Linear Regression}

The relationship of fatigue damage coefficient and geometric dimensions of pressurized lateral nozzle with local wall thinning was obtained by multiple linear regression. Dimensionless relations were assumed as follows.

$$
\begin{aligned}
s & =\lambda_{2}\left(\frac{\alpha}{90^{\circ}}\right)^{\eta_{1}}\left(\frac{L}{L_{d}}\right)^{\eta_{2}}\left(\frac{H}{t}\right)^{\eta_{3}}\left(\frac{B}{90^{\circ}}\right)^{\eta_{4}} \\
\frac{D_{s}}{D_{s w}} & =\mu_{1}\left(\frac{\alpha}{90^{\circ}}\right)^{\rho_{1}}\left(\frac{L}{L_{d}}\right)^{\rho_{2}}\left(\frac{H}{t}\right)^{\rho_{3}}\left(\frac{B}{90^{\circ}}\right)^{\rho_{4}}
\end{aligned}
$$

Taking the logarithm on both sides of Eq. (6) and Eq.(7), provides,

$$
\begin{gathered}
\ln \left(D_{s}\right)=\eta_{1} \ln \left(\frac{\alpha}{90^{\circ}}\right)+\eta_{2} \ln \left(\frac{L}{L_{d}}\right)+\eta_{3} \ln \left(\frac{H}{t}\right)+\eta_{4} \ln \left(\frac{B}{90^{\circ}}\right)+\ln \lambda_{2} \\
\ln \left(\frac{D_{s}}{D_{s w}}\right)=\rho_{1} \ln \left(\frac{\alpha}{90^{\circ}}\right)+\rho_{2} \ln \left(\frac{L}{L_{d}}\right)+\rho_{3} \ln \left(\frac{H}{t}\right)+\rho_{4} \ln \left(\frac{B}{90^{\circ}}\right)+\ln \mu_{1}
\end{gathered}
$$


The parameter $y_{2}$ and $y_{3}$ represented $\ln \left(D_{s}\right)$ and $\ln \left(\frac{D_{s}}{D_{s w}}\right)$, respectively. $\alpha_{0}, x_{1}, x_{2}, x_{3}$ and $x_{4}$ denoted respectively $\ln u_{1}, \ln \left(\frac{\alpha}{90^{\circ}}\right), \ln \left(\frac{L}{L_{d}}\right), \ln \left(\frac{H}{t}\right)$ and $\ln \left(\frac{B}{90^{\circ}}\right)$. The general forms of multiple linear regression models were expressed by Eq. (10) and Eq. (11).

$$
\begin{aligned}
& y_{2}=\eta_{1} x_{1}+\eta_{2} x_{2}+\eta_{3} x_{3}+\eta_{4} x_{4}+\eta_{0} \\
& y_{3}=\rho_{1} x_{1}+\rho_{2} x_{2}+\rho_{3} x_{3}+\rho_{4} x_{4}+\rho_{0}
\end{aligned}
$$

where, the parameters $\eta_{1 \sim 4}$ and $\rho_{1 \sim 4}$ were regression coefficients, the parameter $\eta_{0}$ and $\rho_{0}$ was random error. The estimated values were expressed by the parameters $\beta_{0 \sim 4}$. Regression equation was written as follows.

$$
\hat{y}=\beta_{1} x_{1}+\beta_{2} x_{2}+\beta_{3} x_{3}+\beta_{4} x_{4}+\beta_{0}
$$

Regression coefficients and random errors were estimated by the least square method, i.e., when the sum of squared residuals the calculated value $y$ and regression value $\hat{y}$ reached the minimum, the estimated values were deeded as the regression coefficients and random errors of regression equation. According to the statistical analysis software (SPSS), the regression results were written in the following.

Fatigue damage coefficient:

$$
\begin{gathered}
D_{s}=0.014422\left(\frac{L}{L_{d}}\right)^{0.044}\left(\frac{H}{t}\right)^{0.058}\left(\frac{B}{90^{\circ}}\right)^{0.034}\left(\frac{\alpha}{90^{\circ}}\right)^{-4.618} \\
\frac{D_{s}}{D_{s w}}=0.481\left(\frac{L}{L_{d}}\right)^{0.044}\left(\frac{H}{t}\right)^{0.058}\left(\frac{B}{90^{\circ}}\right)^{0.034}\left(\frac{\alpha}{90^{\circ}}\right)^{-4.618}
\end{gathered}
$$

The scope of Eqs.(13) and (14) was $35^{\circ} \leq \alpha \leq 70^{\circ}, 0.0769 \leq L / L_{d} \leq 0.3462,0.1875 \leq H / t \leq 0.7875$, $0.39 \leq \mathrm{B} / 90^{\circ} \leq 0.78$.

Regression coefficient and random error were estimated by least square method, i.e., when the residual square sum of the calculated results and regression results achieved minimum, the regression values were treated as the regression coefficient and random error of regression relations.

SPSS software was used to the regress data in Table 7 and Table 8 . The results were shown in Tables 9-11. Tables 9-11 listed the regression results. The determination coefficient of the regression equation was characterized by the model matrix. The statistic $R^{2}$ indicated the effect of the model on the independent variable. If the $R^{2}$ far was less than one, the fitting effect of the specimen was the better. The $R^{2}$ of the specimen were 0.979 . This showed that the simulation of the model is close to its actual situation. Anova included the degree of freedom, mean square, Square sum significance, and the corresponding $F$ value of the multivariate linear regression model. These were the results of the remarkable $F$ test of the model, and the smaller the value was, the better the simulation effect was. The $F$ validation value in the model was zero, so the simulation effect of the model was very good. The coefficient table mainly included the estimated value of the regression coefficient without standardization and the estimated value of the standardized regression coefficient, the statistical value of the $t$ test and its corresponding significant value. For the same reason, the smaller the values were, the better the effect of the model simulation was. The table showed that the significant value of the $t$ test of each variable was less than 0.4. It can be considered that the simulation of the model was feasible and the obtained results were reliable. 
Table 9 The model matrix of damage coefficient

\begin{tabular}{ccccc}
\hline Model & $\mathrm{R}$ & $\mathrm{R}^{2}$ & Adjustment $\mathrm{R}^{2}$ & Standard estimate error \\
\hline 1 & 0.99 & 0.98 & 0.979 & 0.196 \\
\hline
\end{tabular}

Table 10 Anova

\begin{tabular}{ccccccc}
\hline Model & & Square sum & df & Average & F & Sig \\
\hline \multirow{2}{*}{1} & Regression & 144.78 & 4 & 36.194 & 936.041 & 0 \\
& Residual & 2.939 & 76 & 0.039 & - & - \\
& Total & 147.72 & 80 & - & - & - \\
\hline
\end{tabular}

Table 11 Coefficient

\begin{tabular}{|c|c|c|c|c|c|c|}
\hline \multirow{2}{*}{ Model } & & \multicolumn{2}{|c|}{ Non-standard coefficient } & \multirow{2}{*}{$\begin{array}{c}\text { Standard } \\
\text { coefficient }\end{array}$} & \multirow[t]{2}{*}{$\mathrm{t}$} & \multirow{2}{*}{ Sig } \\
\hline & & $\mathrm{B}$ & Standard error & & & \\
\hline \multirow{5}{*}{1} & (Constant) & -0.953 & 0.134 & - & -7.13 & 0 \\
\hline & In $(\mathrm{L} / \mathrm{D})$ & 0.044 & 0.035 & 0.02 & 1.249 & 0.216 \\
\hline & In $(H / T)$ & 0.058 & 0.035 & 0.027 & 1.658 & 0.101 \\
\hline & In $(B / 90)$ & 0.034 & 0.037 & 0.015 & 0.913 & 0.364 \\
\hline & In $(\mathrm{C} / 90)$ & -4.562 & 0.075 & -0.989 & -61.148 & 0 \\
\hline
\end{tabular}

\section{Conclusions}

In this study, the finite element method was used to determine the remaining structural capacity of lateral nozzles which have been subjected to local wall thinning. The study was divided into two main parts; a stress analysis at the lateral nozzles and piping having wall thinning, and a fatigue analysis of damaged intersections subject to cyclical loading.

In the first part of the study, a finite element analysis (FEA) was carried out for the common cylinder-nozzle intersections with and without local wall thinning, to determine the stress concentration factor (SCF). 3D elements were used for the geometries. In convergence-validation studies, the SCF values obtained for vessels with uniform wall thickness were compared with different defect sizes. Comparisons are also made with results from standard formulae given in the literature, and good agreement is observed. An evaluation is made of the effect on the SCF of the growth of the thinning away from the intersection. Finally, a parametric study was conducted in which the SCF is computed for a number of intersections, initially considered undamaged, and then with wall thinning damage. Charts based on the results were provided for the convenience of engineers. According to orthogonal design method, orthogonal table $\mathrm{L}_{9}\left(3^{4}\right)$ was established in order to analyze the SCF of lateral nozzle with local wall thinning. Dimensionless relation of circumferential and defect length, defect depth, defect width and the angle of the cylinder and nozzle was obtained based on multiple regression method. The scope of the dimensionless relation was $35^{\circ} \leq \alpha \leq 70^{\circ}, 0.0769 \leq L / L_{d} \leq 0.3462,0.1875 \leq \mathrm{H} / \mathrm{t} \leq 0.7875,0.39 \leq B / 90^{\circ} \leq 0.78$.

In the second part of the study, a preliminary fatigue analysis is carried out to compare the performance under cyclic loading of sphere-nozzle and cylinder-nozzle intersections, without and with wall thinning damage. According to orthogonal design method, fatigue damage coefficient and defect length, defect depth, defect width and the angle of the cylinder and nozzle was obtained based on multiple regression method. The scope of the dimensionless relation was $35^{\circ} \leq \alpha \leq 70^{\circ}, 0.0769 \leq$ 


$$
L / L_{d} \leq 0.3462,0.1875 \leq H / t \leq 0.7875,0.39 \leq B / 90^{\circ} \leq 0.78 \text {. }
$$

Acknowledgments

This work was partly supported by the Natural Science Foundation of Hebei Province of China (No. E2018501022), the Fundamental Research Funds for the Central Universities (No. N182304009) and China Postdoctoral Science Foundation Funded Project (No. 2017M610171).

\section{References}

[1] Kubair DV, Bhanu-Chandar B. Stress concentration factor due to a circular hole in functionally graded panels under uniaxial tension. International Journal of Mechanical Sciences, v. 50, pp. 732-742, 2008 .

[2] Qadir M, Redekop D. SCF analysis of a pressurized vessel-nozzle intersection with wall thinning damage. International Journal of Pressure Vessels and Piping, v. 86, pp.541-549, 2009.

[3] Ji J, Zhang CS, Kodikara J, Yang SQ. Prediction of stress concentration factor of corrosion pits on buried pipes by least squares support vector machine. Engineering Failure Analysis, v. 55, pp. 131-138, 2015.

[4] Kharat AR, Kamble SB, Patil AV, Burse ID. Comparative study of different approaches to estimate SCF in pressure vessel opening. Journal of Mechanical Engineering and Technology, v.7, pp. 142-155, 2016.

[5] Zeinoddini M, Peykanu M. Strain ratcheting of steel tubulars with a rectangular defect under axial cycling: A numerical modeling. Journal of Constructional Steel Research, v. 67, pp.1872-1883, 2011.

[6] Miyazaki K, Nebu A, Ishiwata M, Hasegawa K. Fracture strength and behavior of carbon steel pipes with local wall thinning subjected to cyclic bending load. Nuclear Engineering and Design, v. 214, pp. 127-136, 2001.

[7] Balan C, Redekop D. The effect of bi-directional loading on fatigue assessment of pressurized piping elbows with local thinned areas. International Journal of Pressure Vessels and Piping, v. 82, pp. 235-242, 2005.

[8] Kim JW, Lee SH, Park CY. Experimental evaluation of the effect of local wall thinning on the failure pressure of elbows. Nuclear Engineering and Design, v. 239, pp. 2737-2746, 2009.

[9] Takahashi K, Tsunoi S, Hara T, Ueno T, Mikami A, Takada H, Ando K, Shiratori M. Experimental study of low-cycle fatigue of pipe elbows with local wall thinning and life estimation using finite element analysis. International Journal of Pressure Vessels and Piping, v. 87, pp.211-219, 2010.

[10] Nakamura I, Otani A, Shiratori M. Failure behavior of elbows with local wall thinning under cyclic load. ASME PVP, 486: 173-180, 2004.

[11] Shi HR, Chen G, Wang Y, Chen X. Ratcheting behavior of pressurized elbow pipe with local wall thinning. International Journal of Pressure Vessels and Piping, v. 102-103, pp. 14-23, 2013.

[12] Chen XH, Chen X. Study on Ratcheting effect of pressurized straight pipe with local wall thinning using finite element analysis. International Journal of Pressure Vessels and Piping, v. 139, pp. 69-76, 2016. 
[13] Chen XH, Chen X. Effect of local wall thinning on ratcheting behavior of pressurized $90^{\circ}$ elbow pipe under reversed bending using finite element analysis. Steel Composite Structures, v. 20, pp. 931950, 2016.

[14] Zamani SM, Hassanzadeh-Tabrizi SA, Sharific H. Failure analysis of drill pipe: A review. Engineering Failure Analysis. Journal of Petroleum Science and Engineering, v. 59, pp. 605-623,2016.

[15] Mahmoodian M, Li CQ. Failure assessment and safe life prediction of corroded oil and gas pipelines. Journal of Petroleum Science and Engineering, v. 151, pp. 434-438, 2017.

[16] Ji J, Robert DJ, Zhang CS, Zhang D, Kodikara J. Probabilistic physical modelling of corroded cast iron pipes for lifetime prediction. Structural Safety, v. 64, pp. 62-75, 2017. 